\title{
A!
}

This is an electronic reprint of the original article.

This reprint may differ from the original in pagination and typographic detail.

Uusi-Kyyny, Petri; Qureshi, Muhammad Saad; Pokki, Juha Pekka; Alopaeus, Ville; Richon, Dominique

\section{0th Anniversary}

Published in:

Industrial and Engineering Chemistry Research

DOI:

10.1021/acs.iecr.9b02912

Published: 01/01/2019

Document Version

Peer reviewed version

Published under the following license:

Unspecified

Please cite the original version:

Uusi-Kyyny, P., Qureshi, M. S., Pokki, J. P., Alopaeus, V., \& Richon, D. (2019). 110th Anniversary: Critical Properties and High Temperature Vapor Pressures for Furan, 2-Methylfuran, 2-Methoxy-2-methylpropane, 2 -

Ethoxy-2-methylbutane, n-Hexane, and Ethanol and Bubble Points of Mixtures with a New Apparatus. Industrial and Engineering Chemistry Research, 58, 22350-22362. https://doi.org/10.1021/acs.iecr.9b02912

This material is protected by copyright and other intellectual property rights, and duplication or sale of all or part of any of the repository collections is not permitted, except that material may be duplicated by you for your research use or educational purposes in electronic or print form. You must obtain permission for any other use. Electronic or print copies may not be offered, whether for sale or otherwise to anyone who is not an authorised user. 


\title{
110th Anniversary: Critical properties and high temperature vapor pressures for furan, 2-methylfuran, 2-methoxy-2-methylpropane, 2- ethoxy-2-methylbutane, $n$-hexane and ethanol, and bubble points of mixtures with a new apparatus
}

\author{
Petri Uusi-Kyyny $^{1 *}$, Muhammad Saad Qureshi' ${ }^{1}$, Juha-Pekka Pokki ${ }^{1}$, Ville Alopaeus ${ }^{1}$ and \\ Dominique Richon ${ }^{1,2}$ \\ ${ }^{1}$ Aalto Univ, School of Chemical Engineering, Department of Department of \\ Chemical and Metallurgical Engineering, FI-00076 Aalto, Finland. \\ 2 Thermodyn. Res. Unit, School of Chemical Engineering, Howard College Campus, \\ University of KwaZulu-Natal, King George V Avenue, 4041 Durban, South Africa.
}

*Corresponding author, petri.uusi-kyyny@aalto.fi

\begin{abstract}
A new improved apparatus is presented for measurements of critical points and vapor pressures of pure compounds. Additionally, with this apparatus it is possible to measure bubble and critical points of mixtures. The experimental temperature range is from $298 \mathrm{~K}$ to $673 \mathrm{~K}$ and the experimental pressure range is from 0 to a maximum of $20 \mathrm{MPa}$. Measurements of pure component vapor pressures and critical points are presented for ethanol, n-hexane, furan, 2-methylfuran, 2-methoxy-2-methylpropane (MTBE), and 2-ethoxy-2-methylbutane (TAEE). The measured properties are compared to literature data if available. The vapor pressure correlation of Wagner is used to correlate the measured vapor pressure data.

Measurements of critical and bubble point of mixtures are presented for the ethanol $+\mathrm{n}$ hexane system and are well in-line with literature data. Bubble and critical point measurements are presented for the furan $+n$-hexane mixture, where no literature data is available. The measured bubble points of mixtures are modelled with the Soave-RedlichKwong equation of state. The optimization of its binary interaction parameters is based on the bubble point measurements enabling the modeling of the critical loci of the mixture.
\end{abstract}

Keywords: High pressures, High temperatures, Critical point, Isothermal VLE data, New equipment, dynamic-synthetic method, Modelling, 


\section{Introduction}

Critical points and saturated vapor pressures are among the most fundamental physical properties for pure components. Critical properties and bubble points of mixtures are extremely useful data for chemical engineering modeling purposes and process designs. ${ }^{1,2}$

Some components are reactive close to the critical temperature. The reactivity of the components suggests the use of the Dynamic-Synthetic method for the determination of the critical properties ${ }^{3}$. This method is also called the flow method. ${ }^{4}$ The critical phase transition is detected visually in the Dynamic-Synthetic method. Several research groups have successfully used this method for the measurements of critical properties. ${ }^{5-10}$ The structure of the cell for visual observations is similar among the literature sources. This work attempts to improve the temperature uniformity of the cell during measurement using a new geometry. The apparatus development is based on the work of Soo et al. (2010). ${ }^{5}$ Furthermore, for the successful operation of the dynamic method it is necessary to control the vapor-liquid interface level. A new alleviating method for the level control is presented.

The new modified apparatus is used for measuring critical temperature, critical pressure and vapor pressures of pure components. Furthermore, mixture critical temperatures and pressures as well as bubble point pressures are measured. Validation of the equipment performance for pure components was achieved by measuring critical temperature, critical pressure and vapor pressures of ethanol, n-hexane and 2-methoxy-2-methylpropane (MTBE). Comparison of the measured critical point data with evaluated published work is made for these components. ${ }^{11}$ Additionally, the vapor pressures measured are compared with literature data (references in chapter 5.2). Measurements for furan, 2-methylfuran, and 2-ethoxy-2-methylbutane (TAEE) are presented. Measured critical temperature and critical pressure for TAEE, a fuel oxygenate, have not been previously available.

Critical point measurements for mixtures are presented for ethanol $+n$-hexane and furan $+n$ hexane. The measurements for ethanol $+\mathrm{n}$-hexane are used for equipment validation and are compared with measurements available from the literature.12-16 For the furan $+n$-hexane system comparison is not possible due to lack of literature data. The bubble point pressures of ethanol $+\mathrm{n}$-hexane and furan $+\mathrm{n}$-hexane were also measured at elevated temperatures and pressures.

The pure components vapor pressure are modeled using the Wagner Equation. ${ }^{17,18}$ While the Soave-Redlich-Kwong Equation of state ${ }^{19}$ is used for mixture bubble point and critical point modeling. The Redlich-Kister model was used for correlating the critical pressure and the critical temperature of the mixtures. ${ }^{20}$

\section{Equipment}

The equipment utilizes the dynamic synthetic method, with the visual observation observation of the phase behavior. The critical point measurement apparatus presented in this work can be safely operated at temperatures from $298 \mathrm{~K}$ to $673 \mathrm{~K}$ and at pressures from 0 to $20 \mathrm{MPa}$. The feed is continuously pumped through the apparatus. The principle of the 
measurement method is the visual observation of the critical behavior. A schematic figure of the equipment is given in Figure 1.

Two improvement suggestions of the equipment were tested. The improvement of temperature uniformity in the cell was attempted by using a novel geometry. This is presented in the description of the critical point cell in section 2.1. Furthermore, an easier method to control the level of the vapor-liquid interface in the device was used. The level control method description is given in the experimental procedure chapter 3.2.

\subsection{Critical point cell}

The critical point cell is presented in Figure 2. The novel idea is to perform faster heat transfer and to obtain improved temperature uniformity in the equipment. This idea was investigated by introducing the fluid, through two tube coils. One tube coil is outside the sapphire tube in the oven. This external tube coil pre-heats the fluid close to oven temperature and has been used previously 5 . The new idea is to use a second tube coil in the sapphire tube. The second tube coil helps to reduce time for reaching thermal equilibrium. The tube coil in the sapphire tube can even out the temperature gradients between the introduced fluid and the content of the cell. The coil in the tube does not hinder the visual observation of the phase behavior.

The metal parts in Figure 2 were machined from chemically pure titanium (grade 2 titanium). The selection of material was based on titanium's good chemical resistance. Additionally, thermal expansion coefficient of titanium is similar to that of sapphire, helping to seal sapphire-titanium contacts ${ }^{21,22}$. The $1 / 16$ " titanium feed line and outlet line were laser welded to the top flange. The lines were additionally fixed by a small support. The support prevented kinking and stress on the welded tube seams. A platinum probe was used for temperature measurement. The probe (diameter 1/4") was installed using a compression fitting nut and ferrule (Valco). The hole for the temperature probe, threads, and the correct angle for the ferrule, were machined into the top flange. Sealing of the sapphire tube ends was achieved by using either gold or copper gaskets. Gold gaskets are softer than copper gaskets and easier to install. However gold gaskets are also more expensive than copper gaskets. In other words, gold gaskets are most suitable when components and mixtures of the non-fouling type are handled. A drawback of using copper gaskets is the need for very accurate machining of the seal thickness for proper sealing. The cell in the oven is supported by a steel stand. Using the stand enables height and position adjustments of the cell crucial for visual observations.

\subsection{Oven and Camera system}

The position of the oven and camera are shown in Figure 1. The oven was modified from an HP 5890 series gas Chromatograph by removing the detectors and the inlets. A double glassed window assembly was installed. The phase behavior in the tube was 
monitored using a camera (Model GO-2400C-PGE by JAI Company). The camera was assembled on a mini-stative. The feed from the camera was recorded with a PC equipped with National Instruments Vision Builder software. Two lamps were used for illumination. An oven lamp was placed in the oven, and a second lamp was used for back illuminating the sapphire tube.

\section{3. $\quad$ Feed pumping and pressure control}

The feed was pumped using a syringe pump (Isco 100D). The receiving syringe pump (Isco 260D) was operated in a refill flow setting. For bubble point measurements the receiving pump was in the constant pressure mode.

\subsection{Temperatures and Pressures measurements}

The temperature was measured using a Pt-100 probe connected to a Keysight 34972A Digital Multimeter. The measurements were recorded using the Agilent Benchlink software. Temperature calibrations were performed using an ASL F200 Precision Thermometer and a reference Pt-100 probe. The ASL F200 was calibrated against a standard thermometer at the Finnish National Standards Laboratory (MIKES). The estimated extended uncertainty of the digital thermometer was $\pm 0.06 \mathrm{~K}$ (coverage factor $\mathrm{k}=2$ ).

Keysight 34972A Digital Multimeter (uncertainty for this specific pressure measurement $0.00035 \mathrm{MPa}$, using coverage factor $\mathrm{k}=2$ ) equipped with a GE UNIK (absolute) pressure transducer (pressure range 0-10 $\mathrm{MPa}$, uncertainty for this application $0.0004 \mathrm{MPa}$, using coverage factor $\mathrm{k}=2$ ), was used for the pressure measurements. The pressure transducer, which was located in the outlet line of the critical cell was at room temperature. The component or mixture to be measured acted as the pressure transmitting liquid. The calibrations were carried out using a Beamex MC2-PE electronic readout. The readout was equipped with two external pressure modules: EXT60 or EXT600 (uncertainty of calibrator $0.0016 \mathrm{MPa}$, coverage factor $\mathrm{k}=2$ ) . The calibrator is periodically calibrated at Beamex $\mathrm{Oy}$, Finland. The estimated resulting extended uncertainty corresponding to pressure measurements is $0.00235 \mathrm{MPa}$ (coverage factor $\mathrm{k}=2$ ).

\section{Experimental Procedure}

\subsection{Materials}

The materials and their purities are presented in Table 1. Purity of all compounds was checked using gas chromatography, refractive index measurements and Karl-Fischer titrations. The refractive index values were compared against literature values ${ }^{23-28}$.

The pure compounds were degassed in a round bottom flask using an ultrasonic bath for 30 minutes. The temperature of the ultrasonic bath was kept at $273 \pm 1 \mathrm{~K}$ during degassing using ice. The low temperature in the bath reduced loss of material. The mixtures were prepared gravimetrically by adding compounds into a round bottom flask. The degassing was performed similarly as for the pure components. 


\subsection{Critical point measurements of pure components and mixtures procedure}

The feed syringe pump was first evacuated with a vacuum pump. Subsequently a degassed pure compound or a degassed mixture was fed to the feed pump. A portion of the degassed mixture was used for GC-analysis of its composition. Pumping was initiated by opening the valves to the evacuated critical point cell and the receiving pump. The vapor-liquid interface level in the critical cell was adjusted to the middle of the sapphire tube. The interface in the middle of the tube was considered optimal for the measurements. The volumetric flow rates of the feed and the withdrawal pumps were then set to the same rate. Thus, the interface level was easily kept optimal for the observations. This type of level control is an attractive option in comparison to using flow rate regulation with flow control valves.

The critical temperature was searched by changing the oven temperature. The critical point was detected using visual observation. At the critical point the meniscus either disappeared or reappeared. Typical temperature and pressure profiles of a run for furan is presented in Figure 3. The run consisted of start-up, vapor pressure measurements and critical point determinations. Several repeat critical point determinations were made for each system. The fluctuations appearing in Figure 3 are intentional pressure cycles with which the precise location of the critical point is measured. The critical points were determined from still photos and paired up with the recorded temperatures and pressures. One separate zoomed critical point temperature and pressure profile for furan is presented in Figure 4. The visual observations recorded in the run for pure component furan is presented in Figure 5. The recorded time stamp of the visual observation of the critical transition was used to find the corresponding logged temperature and pressure values. These logged times, temperature values and pressure values have been added to Figure 5 for illustrating the measurement method. In Figure 5 it is furthermore, possible to see that titanium tube coil affects the light passing through the tube. This effect is detected at the coil top part by inducing a small shadow. The shadow must not be interpreted as the meniscus. More light passes through the top part of the sapphire tube, since there is no coil causing an intensity decrease. Additionally, a small amount of deposit formed on the tube (red box in Figure 5). The deposit formed does not affect the visual observation of the interface.

The visual observations for the mixture $n$-hexane(1)+furan(2), $(x(1)=0.878)$ system critical point is presented in Figure 6. Similarly, as in Figure 5 the top part of the sapphire tube is brighter due to the titanium tube coil location. Additionally, four videos of the critical transition is presented in the supplementary material for furan(MP4 1 and MP4 2), ethanol (MP4 3) and n-hexane(1)+furan (x(1)=0.878) (MP4 4).

The effect of flow rate (residence time) on the critical properties was assessed. Flow rate values from 0 to $2 \mathrm{~cm}^{3} \cdot \mathrm{min}^{-1}$ are to be preferred. The corresponding residence time can be adjusted from 1 minute up to several hours for stopped flow measurements. The critical temperatures were determined in this work by using the reappearance temperature. The reappearance temperatures gave a smaller scatter in the repeat determinations (especially for mixtures measurements). The reappearance temperature is defined as the temperature, when the first vapor-liquid behavior is observed as the temperature and pressure is lowered. The mixtures initial state is supercritical in the reappearance determination. 


\subsection{Vapor pressure measurement procedure}

The pure compound vapor pressures were measured using a similar level control procedure as described in chapter 3.2. The vapor-liquid interface level was kept in the middle of the sapphire tube. The oven reached rapidly the new set-point temperature. However, it took approximately $30 \mathrm{~min}$ for the cell to reach steady state temperature. The time needed was due to the thermal inertia and large temperature change. The vapor pressure reading was taken once the temperature was steady. Subsequently a new oven set-point temperature could be given.

\subsection{Mixture bubble point measurement procedure}

The feed pump was kept in the constant flow mode for the bubble point measurements. The receiving pump was kept at the constant pressure mode. Initially the system pressure was set to a value higher than the bubble point. In this mode of operation mixing is not necessary, due to the composition uniformity in the cell. The bubble point pressure was visually detected. The pressure was decreased in steps of $0.01 \mathrm{MPa}$. Pressure steps induced a controlled appearance of the vapor phase bubbles. The minimum step was determined by the resolution of the receiving pumps pressure control $(0.01 \mathrm{MPa})$.

\subsection{Post run procedure for detecting possible thermal degradation}

As the measurement temperatures are relatively high especially for bio-compounds which often tend to be reactive at such conditions. It is important to analyze possible composition changes during the experimental run. This was done by making GC-analysis from the used materials collected. The materials were sampled from the receiving pump after the measurements. GC-analysis was performed to detect if any thermal degradation or contamination occurred during the experiments. GC-analyses are very convenient to allow detecting contaminations or formations of decomposition products.

\subsection{Assessment of experimental uncertainties}

The expanded experimental uncertainties $U$ can be given using Eq 1

$$
U=\left(k U_{c}\right)=k \sqrt{\sum\left(U_{i}\right)^{2}}
$$

where $U_{i}$ is the standard uncertainty of each influencing component, $U_{c}$ is the combined standard uncertainty consisting of each influencing factor, and $\mathrm{k}$ is the confidence coefficient or degree. ${ }^{29}$ The standard uncertainties of the influencing components are presented in Table 2 . In this work the confidence coefficient $\mathrm{k}=2$, corresponding to a $95 \%$ confidence degree is used for characterizing the measurements in the tables. The major uncertainty component of the critical temperature and the critical pressure measurements is the visual observations. For the bubble point pressure measurements, the pump set-point resolution is the major uncertainty component. For the vapor pressure measurements, the largest uncertainty sources are the thermometers and pressure meters.

For the mixture compositions the effect of the response factors and the uncertainties in GC areas were considered. The samples were analyzed using gas chromatography (GC). The 
response factor of a component by GC was determined from gravimetrically prepared samples. The response factor $F_{2}$ was obtained using equation (2) as an average of multiple samples $n$. Gravimetrically prepared samples of masses $m_{1}$ and $m_{2}$ were analyzed giving areas $A_{1}$ and $A_{2}$.

$$
F_{2}=\frac{1}{n} \sum_{n=1}^{n}\left(\frac{m_{2} A_{1}}{m_{1} A_{2}}\right)_{n}
$$

The uncertainties of the response factor $F_{2}, U_{F_{2}}$ is obtained using Eq.3,

$$
U_{F_{2}}=k u_{c}=k \sqrt{\left(\frac{\partial F_{2}}{\partial A_{1}}\right)^{2} u_{A_{1}}^{2}+\left(\frac{\partial F_{2}}{\partial A_{2}}\right)^{2} u_{A_{2}}^{2}+\left(\frac{\partial F_{2}}{\partial m_{2}}\right)^{2} u_{m_{2}}^{2}+\left(\frac{\partial F_{2}}{\partial m_{1}}\right)^{2} u_{m_{1}}^{2}}
$$

Where the $u_{A_{1}}$ and $u_{A_{2}}$ are uncertainty in the GC area from repeated injections for component $A_{1}$ and $A_{2} . u_{m_{1}}$ and $u_{m_{1}}$ are the uncertainty of the balance $0.002 \mathrm{~g}$.

The mole fraction $\mathrm{x}_{1}$ in a binary mixture is given by equation (4)

$$
x_{1}=\frac{A_{1} / M_{1}}{A_{1} / M_{1}+F_{2}\left(A_{2} / M_{2}\right)}
$$

Where $M_{1}$ and $M_{2}$ are the molar masses of components 1 and 2, respectively. The uncertainties in composition in mole fraction can thus be determined using equation (5)

$$
U_{x}=k u_{c}=k \sqrt{\left(\frac{\partial x}{\partial A_{1}}\right)^{2} u_{A_{1}}^{2}+\left(\frac{\partial x}{\partial A_{2}}\right)^{2} u_{A_{2}}^{2}+\left(\frac{\partial x}{\partial F_{2}}\right)^{2} u_{F_{2}}^{2}}
$$

\section{Modeling}

\subsection{Pure Component Vapor pressure}

The Wagner equation ${ }^{17}$ modified by Ambrose ${ }^{18}$ presented in Eq 6. was used for modeling the vapor pressures. The parameters of vapor pressure correlation were regressed for four components: furan, 2-methylfuran, 2-methoxy-2-methylpropane and 2-ethoxy-2methylbutane.

$\ln \left(\frac{P_{s a t}}{P_{c}}\right)=\frac{A \tau+B \tau^{1.5}+C \tau^{2.5}+D \tau^{5}}{1-\tau}$

Where $\tau=1-\frac{T}{T_{C}}, T_{C}$ is the critical temperature, $P_{c}$ is the critical pressure, A, B C, and D are the optimized parameters. The initial values for the regression of the parameters were obtained using the method of Forero and Velasquez ${ }^{30}$.

\subsection{Correlation of Critical Temperature and Critical Pressure of mixtures}

The critical temperature and critical pressure of the mixtures were modeled using the flexible Redlich-Kister polynomials ${ }^{20}$. The polynomials are presented in Eq. 7 and Eq. 8. 


$$
T_{12}=x_{1} T_{c, 1}+x_{2} T_{c, 2}+\sum_{j=1}^{n} a_{j} x_{1} x_{2}\left(2 x_{1}-1\right)^{j-1}
$$

where $T_{12}$ is the critical temperature of the mixture, $x_{1}$ and $x_{2}$ are the mole fractions of components 1 and 2, respectively, $T_{c, 1}$ and $T_{c, 2}$ are the critical temperature of components 1 and 2 , respectively, and $a_{j}$ are adjustable parameters.

$P_{12}=x_{1} P_{c, 1}+x_{2} P_{c, 2}+\sum_{j=1}^{n} b_{j} x_{1} x_{2}\left(2 x_{1}-1\right)^{j-1}$

where $P_{12}$ is the critical pressure of mixture, $x_{1}$ and $x_{2}$ are the mole fractions of components 1 and 2. respectively, $P_{c, 1}$ and $P_{c, 2}$ are the critical pressures of components 1 and 2 . respectively, $b_{j}$ are adjustable parameters.

\subsection{Bubble points and Critical Points of mixtures based on the equation of state}

The bubble point and the critical point measurements of all the systems were modelled using the Soave-Redlich-Kwong ${ }^{19}$ (SRK) equation of state (EOS) with quadratic mixing rules of the attraction parameter and the linear mixing rule of co-volume. The technique of Heidemann and Khalili ${ }^{31}$ uses volume $\mathrm{V}$ and temperature $\mathrm{T}$ as variables. Thus the SRK equation of state is presented in the form of component mole numbers $n_{i}$ and total moles $\mathrm{n}$ as presented by Mollerup and Michelsen ${ }^{32}$ in Equations from 9 to 16.

$$
p=\frac{n R T}{V-B}-\frac{D}{V(V+B)}
$$

where $\mathrm{R}$ is ideal gas constant, $\mathrm{B}$ covolume term and $\mathrm{D}$ attraction term. The attraction and covolume term expressed in mole numbers comes

$$
B=n b=\sum_{i=1}^{C} n_{i} b_{i}
$$

where covolume term of pure component is

$$
b_{i}=\frac{(\sqrt[3]{2}-1)}{3} \frac{R T_{c, i}}{p_{c, i}} \approx 0.08664 \frac{R T_{c, i}}{p_{c, i}}
$$

and where $T_{c, i}$ and $p_{c, i}$ are the critical temperature and the critical pressure of pure component. The mixing rule for the attraction term is

$$
D=n^{2} a(T)=\sum_{i=1}^{C} \sum_{j=1}^{C} n_{i} n_{j} a_{i j}(T)
$$


where $\mathrm{a}_{\mathrm{ij}}$ comes from binary interaction parameter $\mathrm{k}_{\mathrm{ij}}$, temperature dependency $\alpha_{\mathrm{i}}$ and attraction $\mathrm{a}_{\mathrm{c}, \mathrm{i}}$ terms of pure components

$$
a_{i j}(T)=\left(1-k_{i j}\right) \sqrt{a_{c, i} a_{c, j} \alpha_{i}(T) \alpha_{j}(T)}
$$

The attraction term of pure component $\mathrm{a}_{\mathrm{c}, \mathrm{i}}$ is

$$
a_{c, i}=\frac{1}{9(\sqrt[3]{2}-1)} \frac{R^{2} T_{c, i}^{2}}{p_{c, i}} \approx 0.42748 \frac{R^{2} T_{c, i}^{2}}{p_{c, i}}
$$

The temperature dependency $\alpha_{i}$ of attraction term comes from

$$
\begin{aligned}
& \alpha_{i}^{0.5}=1+m_{i}\left(1-\sqrt{T / T_{c, i}}\right) \\
& m_{i}=0.48+1.574 \omega_{i}-0.176 \omega_{i}^{2}
\end{aligned}
$$

where $\omega_{\mathrm{i}}$ is the acentric factor of pure component. The acentric factor of furan was calculated based on the pure component vapor pressure measurements $(\omega=0.2102)$. The $n$-hexane and ethanol acentric factors were obtained from the literature. ${ }^{33}$

The presentation by Mollerup and Michelsen ${ }^{32}$ is a systematic way for computing the fugacity, fugacity coefficient and other derived properties using the cubic EOS. The bubble point pressure is calculated with the standard phase equilibrium routines and the critical point of mixture with the technique presented by Heidemann and Khalil ${ }^{31}$. The method of Heidemann and Khalil calculates the critical point of a mixture directly without any need of bubble or dew point calculation. This independence is beneficial because the binary interaction parameter of EOS was optimized first based on the bubble point measurements and then optimized parameters were used in the critical point calculation. The alternative of having the binary interaction parameter set to zero was also evaluated.

\section{Results and Discussion}

\subsection{Critical points of pure compounds}

The vapor-liquid interface level control was effortless using the new method. However, the new cell geometry did provide some but by no means any substantial improvement to the critical property measurement uncertainty. Pure component critical temperatures and critical pressures were measured for $n$-hexane, ethanol, furan, 2-methylfuran, 2-methoxy-2methylpropane and 2-ethoxy-2-methylbutane. The critical temperatures and pressures are presented in Table 3 together with literature results. Our data agree within experimental 
uncertainty with the recommended values presented in the literature ${ }^{11}$ for ethanol, n-hexane and 2-methoxy-2-methyl-propane.

This work presents a critical pressure value for furan, which has lower uncertainty than the only value previously reported 34 . For the furan critical temperature two literature sources are available. ${ }^{34,35}$ These literature values are within the experimental uncertainty of this work.

Critical temperature and pressure of 2-methylfuran were found in one literature source ${ }^{34}$. The uncertainty in the critical pressure of 2-methylfuran ${ }^{34}$ is within the experimental uncertainty of this work. This work presents a critical temperature value for 2-methylfuran, which has lower uncertainty than the value previously reported ${ }^{34}$. Additionally, the critical temperature and the critical pressure for 2-ethoxy-2-methylbutane is measured in this work. The measurements presented for the critical properties of 2-ethoxy-2-methylbutane are currently the only values available.

\subsection{Vapor pressures of pure compounds}

The results of the vapor pressure measurements are presented in Table 4. The reliability of the continuous flow method for vapor pressure measurements was verified. This verification was performed by measuring the vapor pressures of ethanol and n-hexane. The vapor pressures of ethanol and n-hexane are compared against a correlation presented in the literature. ${ }^{33}$ The comparison is given in Table 5. The literature correlation is in-line with the measured vapor pressure values for $n$-hexane and ethanol. The relative absolute average deviation (RAAD) for $n$-hexane was $0.9 \%$ and the absolute average deviation was $0.025 \mathrm{MPa}$. For ethanol a RAAD of $0.8 \%$ was obtained and the absolute average deviation was $0.012 \mathrm{MPa}$. These deviations are within the uncertainty of the correlation used. This means that accurate vapor pressure measurements using this method and equipment is possible.

Subsequently vapor pressure measurements were conducted for furan and 2-methylfuran. Vapor pressure measurements near the critical point are scarce for these chemicals.

Vapor pressure measurements for 2-methoxy-2-methylpropane and 2-ethoxy-2methylbutane are presented. The measurements were performed at elevated pressures. There is a large scatter among the high-pressure data available in the vicinity of the critical point.

The regressed vapor pressure correlation parameters are presented in Table 5. The regression was performed using the vapor pressure data sets from this work and the literature (Furan ${ }^{36-39}$, 2-methylfuran $34,37-41,2$-methoxy-2-methylpropane ${ }^{42-46}$, 2-ethoxy-2methylbutane $27,43,47,48)$. The data sets used in the regression were mainly high-pressure data sets. Some data sets with measurements below the atmospheric pressure were also included. The low-pressure data sets were subjectively selected. The high-pressure measurements are scarce for the systems measured in this work for all components. The combined absolute average deviations of pressure for all the measurements from this work and the selected literature sources are presented in Table 5. The vapor pressure residual plots of the correlation with the data are presented in Figures 7 to 10. The residual values from the 
literature and the measurements in this work are shown. The plots are given for furan, 2methylfuran, 2-methoxy-2-methyl-propane and 2-ethoxy-2-methylbutane respectively.

\subsection{Critical points and bubble points of mixtures}

Critical point and bubble point measurements for $n$-hexane + ethanol system are presented in Table 6 and in Figures 11 and 12. The critical point and bubble point measurements for $n-$ hexane + furan system are presented in Table 7 and Figure 13. Critical point and bubble point measurements for the n-hexane + ethanol system was used to validate the measurement method. Results of the measurements are presented in Table 6 and in Figure 11, with the measurements available from the literature ${ }^{5,12-16}$ and a literature correlation ${ }^{5}$ based on the Redlich-Kister polynomials ${ }^{20}$ for describing the critical pressure and critical temperature as a function of composition. The parameters of the Redlich-Kister model are presented in Table 8. Additionally, Table 8 shows the absolute average deviations of the model vs. measurements of this work and the literature.

The binary interaction parameter values of SRK for the n-hexane + ethanol are presented in Table 9. Moreover, Table 9 contains absolute average deviations for bubble point pressure for this work and for literature values ${ }^{12,13}$. These literature values were selected since they are measured at high pressures and high temperatures. The use of the binary interaction parameter regressed from bubble point measurements improves the description of the critical point of the mixtures compared to set the interaction parameter value to zero. The computed bubble point pressures and critical pressures are presented in Figure 11 in addition to the critical points presented in Figure 12.

For the n-hexane + furan system a type 1 behavior according to the classification of van Konynenburg \& Scott ${ }^{49}$ was observed. Low pressure VLE-measurements at $101.325 \mathrm{kPa}$ were available for this system ${ }^{50}$. The critical pressures and critical temperatures were correlated using the Redlich-Kister polynomials ${ }^{20}$. The parameters and the absolute average deviations are presented in Table 9. The critical locus with models is shown in Figure 13.

Soave-Redlich-Kwong equation of state binary interaction parameter was regressed. The bubble point measurements of the n-hexane + furan system were used for the regression. The use of the regressed binary interaction parameter improves the description of the critical locus. In contrast of using the EoS with an interaction parameter value of zero. However, the improvement was less substantial in comparison to what was observed for the $\mathrm{n}$-hexane + ethanol system. It is also interesting to note that the SRK equation of state could describe the atmospheric pressure VLE of Nala et al. ${ }^{50}$ reasonably well. The residuals for Nala et al. ${ }^{50}$ VLE are presented in Table 9. The binary interaction parameter regressed from bubble point data measured in this work at high temperature and pressure was used. By setting the binary interaction parameter to a value of zero substantially higher residuals were observed in comparison to Nala et al ${ }^{50}$ data.

Some challenges were encountered during the measurements. The n-hexane + furan system formed a durable inert resin like heavy deposit during the experiments. The deposit 
formation was slow (several days of running). The accumulation was detected in the coiled titanium tubes. In addition, also the sapphire tube collected deposit. The deposit in the sapphire tube prevented eventually proper visual observation of the interface. The location of the deposit can be seen in the red box in Figure 5 (Photograph 1). Apparatus disassembly, cleaning and reassembly was thus needed every second week for the furan and 2methylfuran systems. Samples were taken of used furan and 2-methylfuran and analyzed using GC. Additional impurity peaks from the GC-analysis were not found. This suggests, that the formed deposit cannot be vaporized, and the decomposition products are of high molar mass. This observation may be of practical importance when designing novel biorefinery processes where these components are treated at harsh conditions.

\section{Conclusions}

A new equipment for the critical temperature and pressure measurements is presented. This new equipment utilizes the dynamic synthetic technique. The apparatus can also be used for vapor pressure measurements of pure components and bubble point measurements of mixtures. The equipment can be operated at a maximum temperature of $673 \mathrm{~K}$ and at a maximum pressure of $20 \mathrm{MPa}$. The level control of the equipment is simple by using two syringe pumps. These pumps enable the control of the feed rate and the withdrawal rate of the components accurately. Additionally, a design for improving the temperature uniformity was tested. The new cell geometry did provide some but by no means any substantial improvement to the critical property measurement uncertainty. The new equipment was used for measuring critical points of pure components and mixtures. In addition, vapor pressures of pure components and bubble points of mixtures were measured.

Critical points were determined for pure components: n-hexane, ethanol, furan, 2methylfuran 2-methoxy-2-methylpropane and 2-ethoxy-2-methylbutane. The critical temperature and critical pressure of 2-ethoxy-2-methylbutane has not been available in the literature previously. The values measured for the other components in this work and the literature data are within experimental uncertainty.

The equipment has been tested by measuring vapor pressures of pure components considered as reference components (n-hexane, ethanol). The results were within experimental uncertainty. Furthermore, new data for furan, 2-methylfuran, 2-methoxy-2methylpropane and 2-ethoxy-2-methylbutane was measured. All the new values compared within the experimental uncertainty to literature data, when available.

Critical pressures and critical temperatures for mixtures were measured for the n-hexane + ethanol system. In addition, high temperature bubble points were determined. These measurements were well in line with the literature data. The critical temperatures and critical pressures of the system were modeled using the SRK EOS. The binary interaction parameter was regressed from the bubble point data and it improved the modelled critical loci substantially. The modeling of the critical temperatures and pressures was successful.

Bubble points and critical points of the n-hexane + furan system was measured. The critical locus was correlated successfully using a Redlich-Kister polynomial. Also, the Soave-Redlich- 
Kwong equation of state was used to model the critical points of the n-hexane + furan system successfully. Regression of the interaction parameter using the bubble point data improves the description of the critical pressure and critical temperature.

\section{Acknowledgments}

University of KwaZulu Natal (Durban, South Africa) and Aalto University (Finland) are acknowledged for their financial supports.

Tekes - the Finnish Funding Agency for Innovation, FiDiPro - Program is acknowledged for funding the FiDiPro position of D. Richon.

Many thanks to Neste Oil, (www.nesteoil.com), Neste Jacobs, (www.nestejacobs.com), UPM, (www.upm.com/en/), Borealis, (www.borealis.com/) for fruitful collaboration and discussions.

Petri Uusi-Kyyny acknowledges the Academy of Finland for its financial support (Decision number 252664).

Support to Aalto University's BIOECONOMY infra by Academy of Finland is acknowledged.

\section{Supporting Information}

Four MP4 -files, which contain critical transitions:

Furan:

MP4 1

furan_meniscus_dissappears_17_28_19-Segment 1(2).mp4

MP4 2

furan_meniscus_reappears_17_29_20-Segment 1(1)(1).mp4

Ethanol:

MP4 3

Ethanol_meniscus_reappears_15_26_20-15_28_40-Segment 1.mp4

Furan+n-Hexane:

MP4 4

furan+hexane_meniscus_reappears-Segment 1.mp4 


\section{References}

(1) Sadus, R., J. Calculating critical transitions of fluid mixtures: Theory vs. experiment. AIChE J. 1994, 40, 1376-1403.

(2) Stradi, B.A.; Brennecke, J., F.; Kohn, J., P.; Stadtherr, M., A. Reliable Computation of Mixture Critical Points. AIChE J. 2001, 47, 212-221.

(3) Dohrn, R., Fonseca, J.M.S., Peper, S. Experimental methods for phase equilibria at high pressures. Annu. Rev. Chem. Biomol, 2012, 3, 343-367.

(4) Teja, A. S.; Mendez-Santiago, J. Critical Parameters Chapter 16 in: Measurement of the thermodynamic properties of multiple phases. Experimental Thermodynamics, Volume VI, R.D. Weir, Th.W.de Loos, eds. Elsevier, Amsterdam, 2005. pp. 410-425. ISBN: 0444519777.

(5) Soo, C.-B.; Théveneau, P.; Coquelet, C.; Ramjugernath, D.; Richon, D. Determination of critical properties of pure and multi-component mixtures using a "dynamic-synthetic" apparatus. J. Supercrit. Fluid. 2010, 55, 545-553.

(6)Rosenthal, D.J.; Teja, A.S. The critical properties of n-alkanes using a low-residence time flow apparatus. AIChE J., 1989, 35, 1829-1834.

(7) Gil, L.; Otín, S.F.; Embid, J.M.; Gallardo, M.A.; Blanco, S.; Artal, M.; Velasco, I.; Experimental setup to measure critical properties of pure and binary mixtures and their densities at different pressures and temperatures. Determination of the precision and uncertainty in the results. J. Supercrit. Fluid. 2008, 44, 123-138.

(8) Horstmann, S.; Fischer, K.; Gmehling, J.; Kólař, P. Experimental determination of the critical line for (carbon dioxide + ethane) and calculation of variousthermodynamic properties for (carbon dioxide + n-alkane) using the PSRK model. J. Chem. Thermodyn. 2000, $32,451-464$.

(9) Juntarachat, N.; Beltran Moreno, P.D.; Bello, S.; Privat, R.; Jaubert, J.-N. Validation of a new apparatus using the dynamic and static methods for determining the critical properties of pure components and mixtures. J. Supercrit. Fluid. 2012, 68, 25-30.

(10) Wang, C.; Chen, J.; Salman, M.; Liu, X.; Zhang, Y.; He, M. Measurement of Critical Properties for Binary and Ternary Mixtures Containing n -Butanol and n -Alkane. J. Chem. Eng. Data 2018, 63, 3956-3965.

(11) Ambrose, D.; Tsonopoulos, C.; Nikitin, E. D.; Morton, D., W.; Marsh, K., N. Vapor-Liquid Critical Properties of Elements and Compounds. 12. Review of Recent Data for Hydrocarbons and Non-hydrocarbons. J. Chem. Eng. Data 2015, 60, 3444-3482.

(12) Sauermann, P.; Holzapfel, K.; Oprzynski, J.; Kohler, F.; Poot, W.; de Loos, Th. W. The ppT properties of ethanol + hexane. Fluid Phase Equilib. 1995, 112, 249-272.

(13) Seo, J.; Lee, J.; Kim, H. Isothermal vapor-liquid equilibria for the system ethanol and nhexane in the near critical region. Fluid Phase Equilib. 2001, 182, 199-207. 
(14) Morton, D. W.; Lui, M.P.W.; Young, C.L. The (gas + liquid) critical properties and phase behavior of some binary alkanol (C2-C5) + alkane (C5-C12) mixtures. J. Chem. Thermodyn. 2003, 35, 1737-1749.

(15) Han, K.; Xia, S.; Ma, P.; Yan, F.; Liu, T. Measurement of critical temperatures and critical pressures for binary mixtures of methyl tert-butyl ether (MTBE)+alcohol and MTBE +alkane. J. Chem. Thermodyn. 2013, 62, 111-117.

(16) Gil, L.; Blanco, S. T.; Rivas, C.; Laga, E.; Fernandez, J.; Artal, M.; Velasco, I. Experimental determination of the critical loci for $\{\mathrm{n}-\mathrm{C} 6 \mathrm{H} 14$ or $\mathrm{CO} 2+$ alkan-1-ol $\}$ mixtures. Evaluation of their critical and subcritical behavior using PC-SAFT EoS. J. Supercrit. Fluids 2012, 71, 26-44.

(17) Wagner, W. New vapour pressure measurements for argon and nitrogen and a new method for establishing rational vapour pressure equations. Cryogenics 1973, 13, 470-482.

(18) Ambrose, D. The correlation and estimation of vapour pressures IV. Observations on Wagner's method of fitting equations to vapour pressures. J. Chem. Thermodyn. 1986, 18, 4551.

(19) Soave, G. Equilibrium constants from a modified Redlich-Kwong equation of state. Chem. Eng. Sci. 1972, 27, 1197-1203.

(20) Redlich, O.; Kister, A. T. Algebraic representation of thermodynamic properties and the classification of solutions. Ind. Eng. Chem. 1952, 48, 345-348.

(21) Baboian, R. (2002). NACE Corrosion Engineer's Reference Book (3rd Edition). NACE International. Online version from https://app.knovel.com/hotlink/toc/id:kpNACECER1/nace-corrosion-engineers/nacecorrosion-engineers (Accessed Sept. 27, 2019)

(22) Moore, J. H.; Davis, C.C.; Coplan, M.A.; Greer, S.A. Building Scientific Apparatus $4^{\text {th }}$ Edition. Cambridge University Press. Online version, 2009. Retrieved from

https://app.knovel.com/hotlink/toc/id:kpBSAE0006/building-scientificapparatus/building-scientific-apparatus (Accessed Sept. 27, 2019)

(23) Guthrie, G. B.; Scott, D. W.; Hubbard, W. N.; Katz, C.; McCullough, J. P.; Gross, M. E.; Williamson, K. D.; Waddington, G. Thermodynamic properties of Furan. J. Am. Chem. Soc. 1952, 74, 4662-4669.

(24) Pryanishinkov, A. A.; Genin, I. L. Azeotropes of 2-methylfuran. Zh. Prikl. Khim. 1940, 13, 140-141.

(25) Schreurs, P. H.; de Jong, A. J.; Brandsma, L. Base-induced ring-opening and ringtransformation of acetylenic epoxides and episulfides. Recl. Trav. Chim. Pays-Bas, 1976, 95, 75-78.

(26) Aim, K.; Ciprian, M. Vapor Pressures, Refractive Index at 20.0 deg C, and Vapor-Liquid Equilibrium at $101.325 \mathrm{kPa}$ in the Methyl tert-Butyl Ether Methanol System, J. Chem. Eng. Data, 1980, 25, 100-103. 
(27) Laavi, H.; Pokki, J. -P.; Uusi-Kyyny, P.; Kim, Y.; Alopaeus, V. Vapor Liquid Equilibrium, Excess Molar Enthalpies, and Excess Molar Volumes of Binary Mixtures Containing 2Ethoxy-2-methylpropane or 2-Ethoxy-2-methylbutane and Acetonitrile or Propanenitrile. J. Chem. Eng. Data 2013, 58, 943-950.

(28) Alonso, E.; Guerrero, H.; Montano, d.; Lafuente, C.; Artigas, H. Thermophysical Study of the n-Hexane or n-Heptane with 1- Chloropropane Systems. Thermochim. Acta, 2011, 525, 71-77.

(29) Working Group 1 of the Joint Committee for Guides in Metrology (JCGM/WG 1), JCGM 1002008 GUM 1995 with minor correction Evaluation of measurement data - Guide to the expression of uncertainty in measurement (2008). https://www.bipm.org/utils/common/documents/icgm/ICGM 1002008 E.pdf (Accessed Sept. 27, 2019)

(30) Forero, L.A.; Velasquez J. A., Wagner liquid-vapour pressure equation constants from a simple methodology. J. Chem. Thermodyn. 2011, 43, 1235-1251.

(31) Heidemann, R.A.; Khalil, A.M., The Calculation of Critical Points. AIChE J. 1980, 26, 769779.

(32) Mollerup, J.M. and Michelsen, M.L., Calculation of Thermodynamic Equilibrium Properties, Fluid Phase Equilib. 1992, 74, 1-15.

(33) Design Institute for Physical Properties, Sponsored by AIChE. (2005; 2008; 2009; 2010; 2011; 2012; 2015; 2016). DIPPR Project 801 - Full Version. Retrieved from

https://app.knovel.com/hotlink/toc/id:kpDIPPRPF7/dippr-project-801-full/dippr-project801-full (Accessed Sept. 27, 2019)

(34) Kobe, K.A.; Ravicz, A.E; Vohra, S.P. Critical Properties and Vapor Pressures of Some Ethers and Heterocyclic Compounds. Ind. Eng. Chem. Chem. Eng. Data Series 1956, 1, 50-56.

(35) Cheng, D. C. H.; McCoubrey, J. C.; Phillips, D. G. Critical Temperatures of Some Organic Cyclic Compounds. Trans. Faraday Soc. 1962, 58, 224-229.

(36) Wilding, W. V.; Wilson, L. C.; Wilson, G. M. Vapor-Liquid Equilibrium Measurements on Ten Binary Systems of Industrial Interest. AIChE Symp. Ser. 1987, 83, 49-69.

(37) Moisejev, V. D.; Antonova, N. D. Vapor pressure and heat of vaporization of some species of furans. Zh. Fiz. Khim. 1970, 44, 2912.-2913.

(38) Tai, W.-P.; Lee, H.-Y.; Lee, M. J. Isothermal vapor liquid equilibrium for binary mixtures containing furfural and its derivatives. Fluid Phase Equilib. 2014, 384, 134-142.

(39) Lomba, L.; Aznar, I.; Gascon, I.; Lafuente, C.; Giner, B. Thermophysical study of the furan family. Thermochim. Acta 2015, 617, 54-64. 
(40) Liebergesell, B.; Kaminski, S.; Pauls, C.; de Loos, Th. W.; Vlugt, T.J.H.; Leonhard, K.; Bardow, A.; Corrigendum to "High-pressure vapor liquid equilibria of the second generation biofuel blends (2-methylfuran + iso-octane) and (2-methyltetrahydrofuran + di-n-butyl ether): Experiments and PCP-SAFT modeling" Fluid Phase Equilib. 400 (2015) 95-102]. Fluid Phase Equilib. 2016, 409, 495-497.

(41) Loras, S.; Aucejo, A.; Monton, J. B.; Wisniak, J.; Segura, H. Phase Equilibria for 1,1,1,2,3,4,4,5,5,5-Decafluoropentane + 2-Methylfuran, 2-Methylfuran + Oxolane, and 1,1,1,2,3,4,4,5,5,5- Decafluoropentane + 2-Methylfuran + Oxolane at $35 \mathrm{kPa}$. J. Chem. Eng. Data 2002, 47, 1256-1262.

(42) Daubert, T. E.; Jalowka, J. W.; Goren, V. Vapor pressure of 22 pure industrial chemicals. AIChE Symp. Ser., 1987, 83, 128-156.

(43) Kraehenbuehl, M. A.; Gmehling, J. Vapor Pressures of Methyl tert-Butyl Ether, Ethyl tert-Butyl Ether, Isopropyl tert-Butyl Ether, tert-Amyl Methyl Ether, and tert-Amyl Ethyl Ether. J. Chem. Eng. Data 1994, 39, 759-762.

(44) Boukais-Belaribi, G.; Belaribi, B. F.; Ait-Kaci, A.; Jose, J. Thermodynamics of isomeric hexynes +MTBE binary mixtures. Fluid Phase Equilib. 2006, 248, 181-190.

(45) Ambrose, D.; Ellender, J. H.; Sprake, C. H. S.; Townsend, R. Thermodynamic properties of organic oxygen compounds. XLIII. Vapour pressures of some ethers. J. Chem. Thermodyn. 1976, 8, 165-178.

(46) Aucejo, A.; Loras, S.; Munoz, R. Isobaric Vapor-Liquid Equilibrium in the Systems 2Methylpentane + Methyl 1,1-Dimethylethyl Ether, + Ethyl 1,1-Dimethylethyl Ether, and + Methy 1,1-Dimethylpropyl Ether. J. Chem. Eng. Data, 1998, 43, 973-977.

(47) Steele, W. V.; Chirico, R. D.; Knipmeyer, S. E.; Nguyen, A. DIPPR Project 821: Vapor Pressure of Organic Chemicals of Industrial Interest - The 1991 Project Results Experimental Results for DIPPR 1990-91 Projects on Phase Equilibria and Pure Component Properties, 1994, DIPPR Data Series No. 2, 154-173.

(48) Sundberg, A. T.; Laavi, H.; Kim, Y.; Uusi-Kyyny, P.; Pokki, J. -P.; Alopaeus, V. Vapor Liquid Equilibria, Excess Enthalpy, and Excess Volume of Binary Mixtures Containing an Alcohol (1-Butanol, 2-Butanol, or 2-Methyl-2-butanol) and 2-Ethoxy-2-methylbutane. J. Chem. Eng. Data 2012, 57, 3502-3509.

(49) Van Konynenburg, P. H.; Scott, R. L. Critical Lines and Phase Equilibria in Binary Van Der Waals Mixtures. Philos. Trans. A Math. Phys. Eng. Sci. 1980, 298, 495-540.

(50) Nala, M.; Auger, E.; Gedik, I.; Ferrando, N.; Dicko, M.; Paricaud, P.; Volle, F.; Passarello, J. P.; de Hemptinne, J. C.; Tobaly, P.; Stringari, P.; Coquelet, C.; Ramjugernath, D.; Naidoo, P.; Lugo, R. Vapour-liquid equilibrium (VLE) for the systems furan + n-hexane and furan + 
toluene. Measurements, data treatment and modeling using molecular models. Fluid Phase Equilib. 2013, 337, 234-245. 
Table 1. List of chemicals with their suppliers and purities.

\begin{tabular}{|c|c|c|c|c|c|c|c|}
\hline Component & Supplier & $\begin{array}{l}\text { CAS } \\
\text { number }\end{array}$ & $\begin{array}{l}\text { Purity } \\
\text { GC } \\
\text { Mass-\% }\end{array}$ & $\begin{array}{l}\text { Purity } \\
\text { Supplier }\end{array}$ & $\begin{array}{l}\text { Water } \\
\text { content } \\
\text { Mass-\% }\end{array}$ & $\begin{array}{l}\operatorname{Exp} \\
\mathrm{nD} \\
\text { at } 20\end{array}$ & $\begin{array}{l}\text { Lit } \mathrm{nD} \\
\text { At } 20^{\circ} \mathrm{C}\end{array}$ \\
\hline Furan & Sigma-Aldrich & $110-00-9$ & 99.99 & $>99.0$ & 0.075 & 1.4214 & $1.4214^{\mathrm{a}}$ \\
\hline 2-methylfuran & Sigma-Aldrich & $534-22-5$ & 99.95 & $>99.0$ & 0.015 & 1.4332 & $1.4332^{\mathrm{b}}$ \\
\hline Ethanol & Altia Oyj & $64-17-5$ & 99.996 & 99.50 & 0.037 & 1.3612 & $1.3616^{c}$ \\
\hline $\begin{array}{l}\text { 2-methoxy-2- } \\
\text { methylpropane }\end{array}$ & Sigma-Aldrich & $1634-04-4$ & 99.86 & & 0.027 & 1.3661 & $1.36892^{\mathrm{d}}$ \\
\hline $\begin{array}{l}\text { 2-ethoxy-2- } \\
\text { methylbutane }\end{array}$ & Aalto University & $919-94-8$ & 99.86 & 99.86 & 0.059 & 1.3911 & $1.39112^{\mathrm{e}}$ \\
\hline n-hexane & Sigma-Aldrich & $110-54-2$ & 99.27 & $>99.0$ & 0.004 & 1.3752 & $1.375062^{\mathrm{f}}$ \\
\hline
\end{tabular}

${ }^{\text {aRef. }}{ }^{23}$; bRef. ${ }^{24}$; cRef. ${ }^{25}$; dRef. ${ }^{26}$; eRef. ${ }^{27}$; ${ }^{\text {f }}$ Ref. ${ }^{28}$ 
Table 2. Uncertainty components (standard uncertainty) of the critical point, bubble point and the vapor pressure measurements.

Critical point measurement

Utemperature $\quad$ K

Visual observation measurement repeatability

Temperature measurement device uncertainty

Temperature calibration uncertainty

Combined uncertainty, $u_{c}$, temperature

from 0.07 to 0.5

0.02

0.01

from 0.10 to 0.54

\begin{tabular}{|c|c|}
\hline upressure & MPa \\
\hline Visual observation measurement repeatability & from 0.01 to 0.04 \\
\hline Pressure calibration uncertainty & 0.0008 \\
\hline Pressure sensor uncertainty, by manufacturer & 0.0002 \\
\hline Display unit\&34091A multiplexer unit, by manufacturer & 0.000175 \\
\hline Combined uncertainty, $\mathbf{u}_{c, \text { pressure }}$ & from 0.01175 to 0.041175 \\
\hline \multicolumn{2}{|l|}{ Bubble point measurement } \\
\hline upressure & MPa \\
\hline Set-point resolution of pump pressure step & 0.005 \\
\hline Pressure calibration uncertainty & 0.0008 \\
\hline Pressure sensor uncertainty, by manufacturer & 0.0002 \\
\hline Display unit\&34091A multiplexer unit, by manufacturer & 0.000175 \\
\hline Combined uncertainty, uc, pressure & 0.006175 \\
\hline Utemperature & $\mathbf{K}$ \\
\hline Temperature measurement device uncertainty & 0.02 \\
\hline Temperature calibration uncertainty & 0.01 \\
\hline Combined uncertainty, $\mathbf{u}_{c, \text { temperature }}$ & 0.03 \\
\hline \multicolumn{2}{|l|}{ Vapor pressure measurement } \\
\hline Upressure & MPa \\
\hline Pressure calibration uncertainty & 0.0008 \\
\hline Pressure sensor uncertainty, by manufacturer & 0.0002 \\
\hline Display unit\&34091A multiplexer unit, by manufacturer & 0.000175 \\
\hline Combined uncertainty, $u_{c}$ & 0.001175 \\
\hline UTemperature & $\mathbf{K}$ \\
\hline Temperature measurement device uncertainty & 0.02 \\
\hline Temperature calibration uncertainty & 0.01 \\
\hline Combined uncertainty, $\mathbf{u}_{c, \text { temperature }}$ & 0.03 \\
\hline
\end{tabular}


Table 3. Comparison between experimental and predicted critical properties of pure furan, 2 methylfuran, ethanol, 2-methoxy-2-methylpropane, 2-ethoxy-2-methylbutane and n-hexane.

\begin{tabular}{|c|c|c|c|c|c|c|}
\hline Component & furan & 2-methylfuran & ethanol & $\begin{array}{c}\text { 2-methoxy-2- } \\
\text { methyl- } \\
\text { propane }\end{array}$ & $\begin{array}{c}\text { 2-ethoxy- } \\
\text { 2-methyl- } \\
\text { butane }\end{array}$ & n-hexane \\
\hline \multicolumn{7}{|c|}{ Critical Temperature / K } \\
\hline This work & $490.3 \pm 0.6$ & $526.3 \pm 1$ & $513.8 \pm 0.2$ & $497.3 \pm 0.4$ & $545.4 \pm 0.4$ & $507.6 \pm 0.6$ \\
\hline Literature & $487.05 \pm 3$ a & $528.0 \pm 2^{\mathrm{a}}$ & $513.9 \pm 0.1^{c}$ & $497.1 \pm 0.2^{c}$ & -- & $507.6 \pm 0.2^{c}$ \\
\hline Literature & $490.25 \pm 0.2^{\mathrm{b}}$ & -- & -- & & -- & -- \\
\hline \multicolumn{7}{|c|}{ Critical Pressure / MPa } \\
\hline This work & $5.63 \pm 0.04$ & $4.60 \pm 0.1$ & $6.17 \pm 0.04$ & $3.49 \pm 0.03$ & $2.76 \pm 0.03$ & $3.04 \pm 0.05$ \\
\hline Literature & $5.323 \pm 0.103^{a}$ & $4.72 \pm 0.103^{a}$ & $6.14 \pm 0.02^{c}$ & $3.43 \pm 0.01^{\mathrm{c}}$ & -- & $3.027 \pm 0.02^{c}$ \\
\hline
\end{tabular}

The combined expanded uncertainties of temperature and pressure in this work were calculated using the coverage factor, $\mathrm{k}=2$. The uncertainty is composed of effect of repeat visual determinations of the critical point and the uncertainty of the measurement devices (pressure and temperature). ${ }^{a}$ Ref. ${ }^{34}$, b Ref. ${ }^{35}$, c. Ref. ${ }^{11}$ 
Table 4. Vapor pressure of furan, 2-methylfuran, ethanol, 2-methoxy-2-methylpropane, 2ethoxy-2-methylbutane and $n$-hexane.

\begin{tabular}{|c|c|c|c|c|c|}
\hline \multicolumn{2}{|c|}{ Furan } & \multicolumn{2}{|c|}{ 2-methylfuran } & \multicolumn{2}{|c|}{ Ethanol } \\
\hline$T / \mathrm{K}$ & $p / \mathrm{MPa}$ & $T / \mathrm{K}$ & $p / \mathrm{MPa}$ & $T / \mathrm{K}$ & $p / \mathrm{MPa}$ \\
\hline 413.71 & 1.673 & 509.06 & 3.663 & 393.53 & 0.426 \\
\hline 423.34 & 1.991 & 513.58 & 3.881 & 413.43 & 0.754 \\
\hline 427.96 & 2.151 & 518.31 & 4.118 & 433.10 & 1.243 \\
\hline 433.21 & 2.360 & 518.55 & 4.127 & 452.61 & 1.934 \\
\hline 437.74 & 2.534 & 523.44 & 4.417 & 473.23 & 2.950 \\
\hline 438.99 & 2.589 & 527.70 & 4.666 & 493.12 & 4.288 \\
\hline 443.71 & 2.796 & & & & \\
\hline 448.68 & 3.028 & & & & \\
\hline 453.33 & 3.253 & & & & \\
\hline 458.22 & 3.503 & & & & \\
\hline 463.01 & 3.716 & & & & \\
\hline 469.23 & 4.134 & & & & \\
\hline 473.78 & 4.424 & & & & \\
\hline 483.79 & 5.102 & & & & \\
\hline \multicolumn{2}{|c|}{$\begin{array}{l}\text { 2-methoxy-2- } \\
\text { methylpropane }\end{array}$} & \multicolumn{2}{|c|}{$\begin{array}{c}\text { 2-ethoxy-2- } \\
\text { methylbutane }\end{array}$} & \multicolumn{2}{|c|}{ n-Hexane } \\
\hline$T / \mathrm{K}$ & $p / \mathrm{MPa}$ & $T / \mathrm{K}$ & $p / \mathrm{MPa}$ & $T / \mathrm{K}$ & $p / \mathrm{MPa}$ \\
\hline 373.34 & 0.362 & 398.00 & 0.191 & 474.26 & 1.824 \\
\hline 423.55 & 1.056 & 413.73 & 0.277 & 478.36 & 1.946 \\
\hline 453.24 & 1.776 & 428.67 & 0.385 & 483.02 & 2.090 \\
\hline 473.65 & 2.451 & 443.89 & 0.530 & 488.27 & 2.260 \\
\hline 483.21 & 2.830 & 458.87 & 0.702 & 493.89 & 2.456 \\
\hline 492.23 & 3.236 & 473.72 & 0.914 & 498.91 & 2.641 \\
\hline \multirow[t]{10}{*}{493.19} & 3.289 & 483.65 & 1.081 & 503.81 & 2.831 \\
\hline & & 493.50 & 1.273 & 505.64 & 2.901 \\
\hline & & 503.40 & 1.487 & 504.46 & 2.872 \\
\hline & & 513.27 & 1.729 & 505.66 & 2.942 \\
\hline & & 523.14 & 1.995 & 507.60 & 2.967 \\
\hline & & 533.00 & 2.301 & 474.36 & 1.831 \\
\hline & & 533.10 & 2.320 & 504.20 & 2.857 \\
\hline & & 542.87 & 2.669 & 472.55 & 1.786 \\
\hline & & 542.94 & 2.666 & 493.80 & 2.472 \\
\hline & & 545.17 & 2.755 & 498.40 & 2.645 \\
\hline
\end{tabular}

$T$ is temperature, $p$ is system pressure. The combined expanded uncertainties of temperature and pressure were calculated using a coverage factor, $\mathrm{k}=2, \mathrm{u}(T)=0.06 \mathrm{~K}, \mathrm{u}(p)=0.0024 \mathrm{MPa}$. 
Table 5. Vapor pressure equation parameters of the Wagner equation for the vapor pressure equations for furan, 2-methylfuran, ethanol, 2-methoxy-2-methylpropane, 2ethoxy-2-methylbutane and n-hexane. Parameters for the vapor pressure correlation regressed in this work (A, B, C, D) with temperature range upper bounds ( $\mathrm{T}_{\text {upper }}$ ) and lower bounds( $\mathrm{T}_{\text {lower }}$ of the correlation based on the measured data in the literature and this work. Absolute average pressure residuals $\left(\Delta \mathrm{P}_{\text {rel }}-\%=100 \cdot\left|\mathrm{P}_{\text {meas }}-\mathrm{P}_{\text {calc }}\right| / \mathrm{P}_{\text {meas }}\right)$

\begin{tabular}{|c|c|c|c|c|c|c|}
\hline Component & n-hexane ${ }^{a}$ & ethanola & furan & 2-methyl-furan & $\begin{array}{c}\text { 2-methoxy-2- } \\
\text { methyl } \\
\text { propane }\end{array}$ & $\begin{array}{c}\text { 2-ethoxy-2- } \\
\text { methylbutane }\end{array}$ \\
\hline \multicolumn{7}{|l|}{ Parameter } \\
\hline A & - & - & $7 . \overline{-} 1717$ & -6.4744 & -7.4791 & -8.2585 \\
\hline B & - & - & 1.924 & -0.43131 & 2.0028 & 3.3028 \\
\hline $\mathrm{C}$ & - & - & 2.2511 & 0.013039 & -2.6043 & -4.7448 \\
\hline $\mathrm{D}$ & - & - & 3.4539 & -4.5076 & -3.3360 & -0.8156 \\
\hline $\mathrm{T}_{\text {lower }}$ & - & & 230.1 & 225.1 & 263.15 & 324.3 \\
\hline $\mathrm{T}_{\text {upper }}$ & - & - & 490.3 & 526.3 & 497.3 & 545.4 \\
\hline$\Delta \mathrm{P}_{\text {rel- }} \%$, this work & 0.91 & 0.76 & 0.4 & 0.7 & 0.1 & 0.3 \\
\hline$\Delta \mathrm{P}_{\text {rel- }} \%$,lit. & - & - & $1.2^{(\mathrm{b})}$ & $0.8^{(b)}$ & $1.0^{(i)}$ & $0.3^{(\mathrm{k})}$ \\
\hline$\Delta \mathrm{P}_{\mathrm{rel}}-\%$, lit. & - & - & $1.1^{(\mathrm{c})}$ & $0.9^{(\mathrm{d})}$ & $0.1^{(\mathrm{k})}$ & $0.5^{(0)}$ \\
\hline$\Delta \mathrm{P}_{\text {rel-}}=\%$, lit. & - & - & $0.2^{(\mathrm{d})}$ & $2.1^{(f)}$ & $0.2^{(\text {(I) }}$ & $0.4^{(\mathrm{p})}$ \\
\hline$\Delta \mathrm{P}_{\text {rel- }} \%$, lit. & - & - & $0.02^{(\mathrm{e})}$ & $0.7^{(g)}$ & $0.2^{(\mathrm{m})}$ & $0.3^{(q)}$ \\
\hline$\Delta \mathrm{P}_{\text {rel- }} \%$, lit. & - & - & $0.7^{(f)}$ & $0.8^{(\mathrm{h})}$ & $0.7^{(\mathrm{n})}$ & - \\
\hline$\Delta \mathrm{P}_{\mathrm{rel}}-\%$, lit. & - & - & $0.2^{(\mathrm{g})}$ & $0.6^{(i)}$ & - & - \\
\hline
\end{tabular}

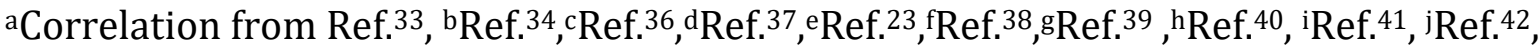

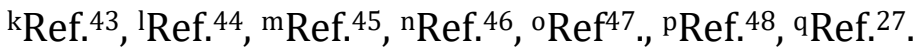


Table 6. Measured bubble points and critical points of $n$-hexane(1) + ethanol.

\begin{tabular}{ccc}
\hline $\boldsymbol{x} \mathbf{1}$ & $\begin{array}{c}\text { Bubble Points } \\
\boldsymbol{T} / \mathbf{K}\end{array}$ & $\boldsymbol{p} / \mathbf{M P a}$ \\
\hline $0.149 \pm 0.003$ & 423.4 & 1.19 \\
$0.149 \pm 0.003$ & 453.8 & 2.21 \\
$0.149 \pm 0.003$ & 483.5 & 4.07 \\
$0.500 \pm 0.005$ & 394.3 & 0.64 \\
$0.500 \pm 0.005$ & 443.3 & 1.95 \\
$0.500 \pm 0.005$ & 473.6 & 3.38 \\
$0.657 \pm 0.005$ & 391.9 & 0.56 \\
$0.657 \pm 0.005$ & 423.3 & 1.18 \\
$0.657 \pm 0.005$ & 473.8 & 3.12 \\
$0.866 \pm 0.003$ & 393.9 & 0.57 \\
$0.866 \pm 0.003$ & 423.9 & 1.17 \\
$0.866 \pm 0.003$ & 453.8 & 1.87 \\
$0.866 \pm 0.003$ & 473.5 & 2.51 \\
\hline $\boldsymbol{x}$ & Critical Points & \\
$0.149 \pm 0.003$ & $\boldsymbol{T} / \mathbf{K}$ & $\boldsymbol{p} / \mathbf{M P a}$ \\
$0.500 \pm 0.005$ & 501.4 & 5.42 \\
$0.657 \pm 0.005$ & 489.3 & 4.24 \\
$0.866 \pm 0.003$ & 493.5 & 3.80 \\
\hline
\end{tabular}

The combined expanded uncertainties of temperature and pressure are calculated using a coverage factor, $\mathrm{k}=2$, for bubble points $u(T)=0.06$ and $u(p)=0.013 \mathrm{MPa}$, for critical points $u(T)=0.4, u(p)=0.04 \mathrm{MPa}$. The uncertainty of the critical point determinations is composed of effect of repeat visual determinations of the critical point in addition to the uncertainty of the measurement devices (pressure and temperature). 
Table 7. Measured Bubble points and critical points of $n$-hexane(1) + furan.

\begin{tabular}{ccc}
\hline & Bubble Points & \\
$\boldsymbol{x}_{\mathbf{1}}$ & $\boldsymbol{T} / \mathbf{K}$ & $\boldsymbol{p} / \mathbf{M P a}$ \\
\hline $0.878 \pm 0.003$ & 463.86 & 1.86 \\
$0.498 \pm 0.005$ & 463.50 & 2.78 \\
$0.318 \pm 0.004$ & 463.80 & 3.21 \\
$0.124 \pm 0.003$ & 463.71 & 3.63 \\
$0.878 \pm 0.003$ & 473.69 & 2.18 \\
$0.498 \pm 0.005$ & 473.92 & 3.22 \\
$0.318 \pm 0.004$ & 473.85 & 3.70 \\
$0.124 \pm 0.003$ & 473.74 & 4.20 \\
\hline & Critical Points & \\
\hline $\mathbf{1}$ & $\boldsymbol{T} / \mathbf{K}$ & $\mathbf{p} / \mathbf{M a}$ \\
\hline $0.678 \pm 0.003$ & 504.13 & 3.24 \\
$0.498 \pm 0.005$ & 498.84 & 4.65 \\
$0.318 \pm 0.004$ & 494.29 & 4.53 \\
$0.124 \pm 0.003$ & 490.22 & 5.13 \\
\hline
\end{tabular}

The combined expanded uncertainties of temperature and pressure are calculated using a coverage factor, $\mathrm{k}$ is equal to 2, for bubble points $u(T)=0.06 \mathrm{~K}$, and $u(p)=0.013 \mathrm{MPa}$, for critical points $u(T)=0.4, u(p)=0.02 \mathrm{MPa}$. The uncertainty of the critical point determinations is composed of effect of repeat visual determinations of the critical point in addition to the uncertainty of the measurement devices (pressure and temperature). 
Table 8. Redlich-Kister parameters describing the critical Temperature ( $a_{1}, a_{2}$ and $\left.a_{3}\right)$ and critical pressure $\left(b_{1}, b_{2}\right.$ and $\left.b_{3}\right)$ as a function of composition in mol fraction for the $n$-hexane + ethanol and n-hexane + furan systems. $A A D$ is the absolute average deviation with respect to temperature (measured-model). RAAD is the relative absolute average deviation with respect to pressure $\left(100^{*}\right.$ (measured-model)/measured)).

\begin{tabular}{|c|c|c|c|c|c|c|c|c|}
\hline & \multicolumn{3}{|c|}{ Temperature Correlation param. } & \multirow{2}{*}{$\begin{array}{c}\text { Temperature } \\
\text { AAD } \\
\text { K } \\
\end{array}$} & \multicolumn{3}{|c|}{ Pressure Correlation param. } & \multirow{2}{*}{$\begin{array}{c}\text { Pressure } \\
\text { RAAD } \\
\Delta \text { P-rel- } \% \\
\end{array}$} \\
\hline & $\mathrm{a}_{1}$ & $\mathrm{a}_{2}$ & $\mathrm{a}_{3}$ & & $b_{1}$ & $b_{2}$ & $\mathrm{~b}_{3}$ & \\
\hline \multicolumn{9}{|c|}{ n-hexane+ethanol } \\
\hline This work & & & & 0.59 & & & & 0.99 \\
\hline a & -84.37 & -27.197 & 18.006 & 0.14 & -1.27 & -1.328 & 0.064 & 0.15 \\
\hline $\mathrm{b}$ & & & & 0.56 & & & & 1.07 \\
\hline c & & & & 2.02 & & & & -- \\
\hline d & & & & 0.51 & & & & 0.74 \\
\hline e & & & & 0.66 & & & & 2.67 \\
\hline \multicolumn{9}{|c|}{ n-hexane+furan } \\
\hline This work & -19.97 & 15.17 & -7.65 & 0.14 & -1.019 & 0.6468 & -1.067 & 0.22 \\
\hline
\end{tabular}

a,ref. ${ }^{5}$; b ref. ${ }^{12}$, cref. ${ }^{14}$ (only critical temperature), ${ }^{\text {dref. }}{ }^{15}$, eRef. ${ }^{16}$. Redlich-Kister Equation Ref. 20 
Table 9. Binary interaction parameters, temperature residuals, and pressure residuals for the description of the phase equilibria using the SRK-equation of state for the mixtures of nhexane+ethanol and n-hexane+furan.

\begin{tabular}{|c|c|c|c|c|c|c|}
\hline $\begin{array}{l}\text { Absolute } \\
\text { Average } \\
\text { Residual }\end{array}$ & $\begin{array}{l}\text { Source } \\
\text { of Data }\end{array}$ & Units & $\begin{array}{c}n- \\
\text { hexane + } \\
\text { Ethanol } \\
\mathbf{k}_{\mathrm{ij}}=\mathbf{0 . 1 3 2} \\
\end{array}$ & $\begin{array}{c}\text { n-hexane } \\
+ \\
\text { Ethanol } \\
\mathbf{k}_{\mathrm{ij}}=0 \\
\end{array}$ & $\begin{array}{c}\text { n-hexane } \\
+ \\
\text { Furan } \\
\mathbf{k}_{\mathrm{ij}}=\mathbf{0 . 0 3 0} \\
\end{array}$ & $\begin{array}{c}\text { n-hexane } \\
+ \\
\text { Furan } \\
\mathbf{k}_{\mathrm{ij}}=\mathbf{0} \\
\end{array}$ \\
\hline$\Delta P_{C}$ & $\begin{array}{l}\text { This } \\
\text { work }\end{array}$ & Rel-\% & 3.7 & 3.0 & 1.1 & 0.7 \\
\hline$\Delta T_{C}$ & $\begin{array}{l}\text { This } \\
\text { work }\end{array}$ & $\mathrm{K}$ & 1.2 & 10.2 & 0.6 & 2.1 \\
\hline$\Delta P_{V L E}$ & $\begin{array}{l}\text { This } \\
\text { work }\end{array}$ & Rel-\% & 7.0 & 20.6 & 0.3 & 3.8 \\
\hline$\Delta P_{V L E}$ & $\mathrm{a}$ & Rel-\% & 4.2 & 20.4 & -- & -- \\
\hline$\Delta P_{V L E}$ & b & Rel-\% & 2.3 & 12.4 & -- & -- \\
\hline$\Delta y_{V L E}$ & c & $\begin{array}{l}\text { Mole } \\
\text { fraction }\end{array}$ & -- & -- & 0.009 & 0.03 \\
\hline$\Delta T_{V L E}$ & c & $\mathrm{K}$ & -- & -- & 0.53 & 2.28 \\
\hline
\end{tabular}

${ }^{a} \operatorname{Ref.}{ }^{12}, \mathrm{~b} \operatorname{Ref}{ }^{13},{ }^{c} \operatorname{Ref}{ }^{50}$ 


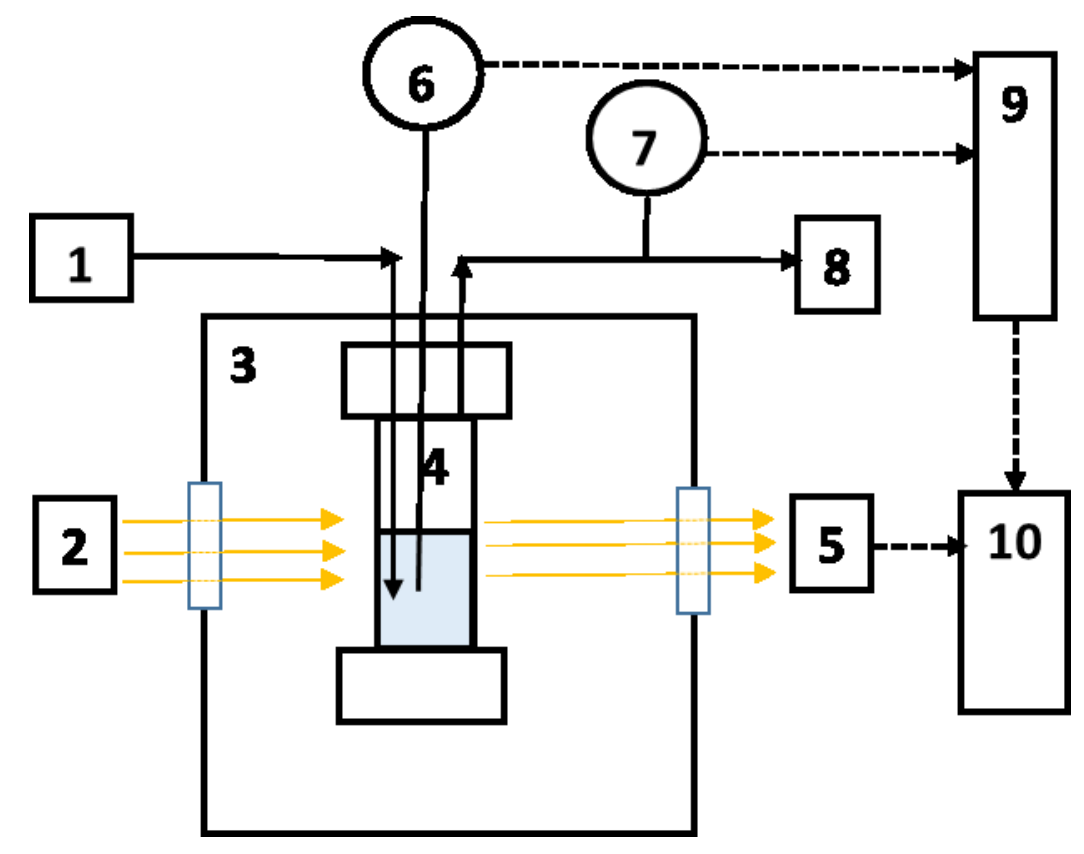

Figure 1. Schematic diagram of the equipment: 1 . Feed pump; 2. Light source; 3. Convection Oven; 4. Critical point cell; 5. Camera; 6. Temperature Probe; 7. Pressure Transducer; 8. Receiving pump; 9. Data Acquisition unit (Keysight 34972A); 10. Personal Computer. Tubing $\longrightarrow$; Electrical signals $\longrightarrow$; Light $=-\rightarrow$. 


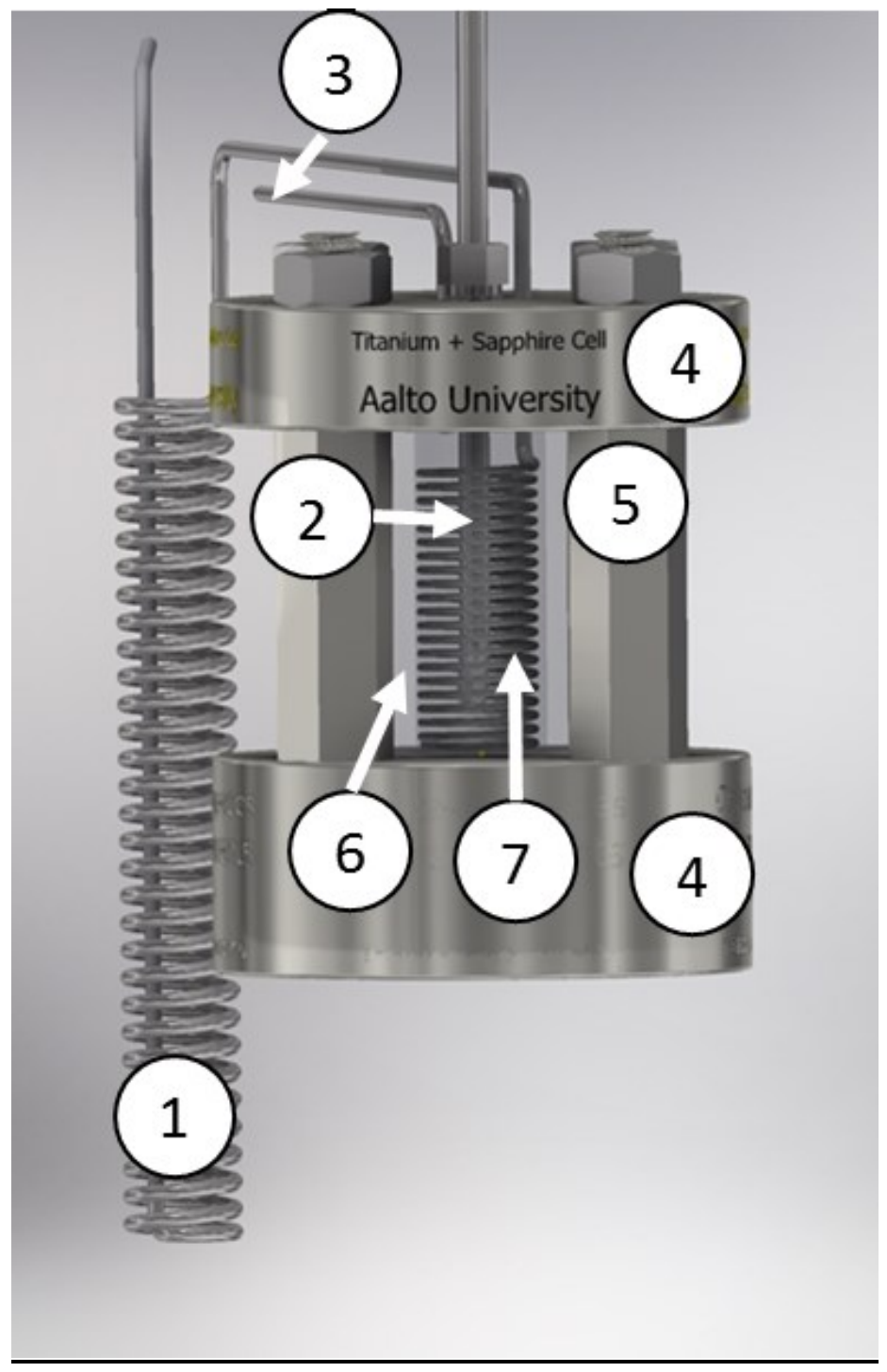

Figure 2. Critical point cell; 1 . Preheater Coil; 2. Temperature probe; 3 . Exit line; 4. Flange; 5. Flange spacer and holder; 6. Sapphire tube; 7. Internal coil for feed introduction, for improved heat transfer, and for improved temperature uniformity inside the sapphire tube. 


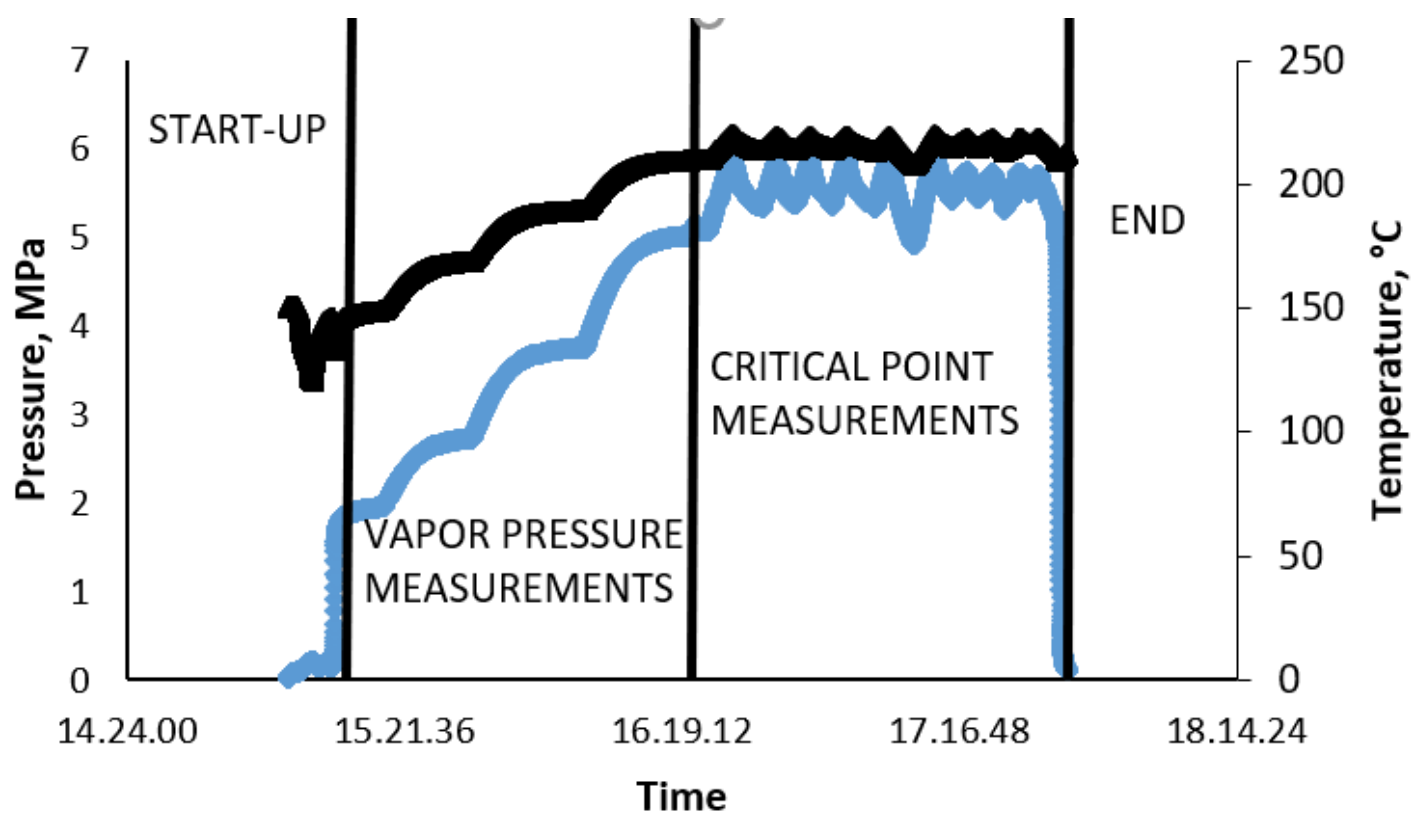

- Pressure $\Delta$ Temperature

Figure 3. Typical measurement sequence (furan) with start-up, vapor pressure measurements ( 4 points), critical point measurements ( 10 repeats) and ending the run. 


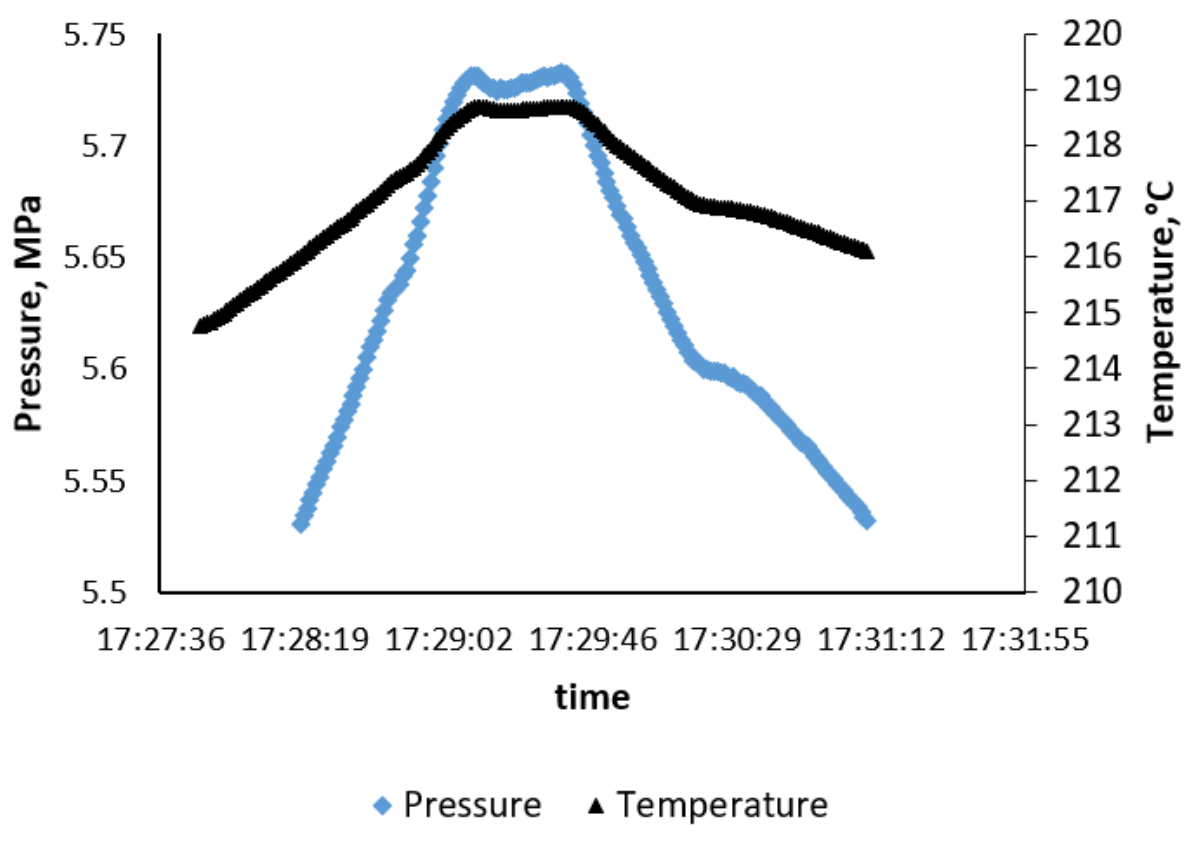

Figure 4. Pressure and Temperature profile for one repeat of critical point determination for Furan. 


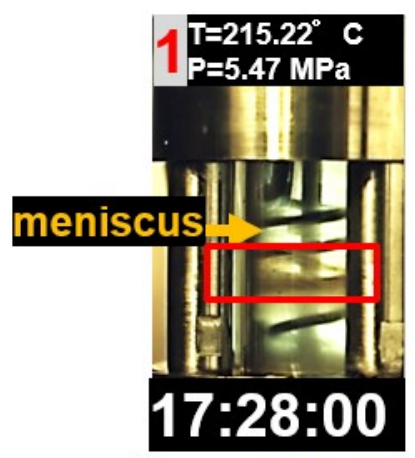

Vapor-Liquid

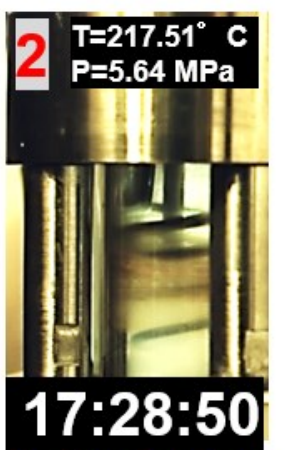

Critical point Meniscus

Dissappears.

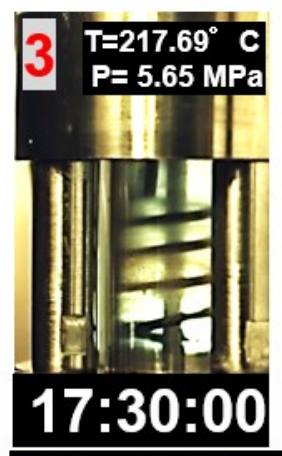

Super Critical
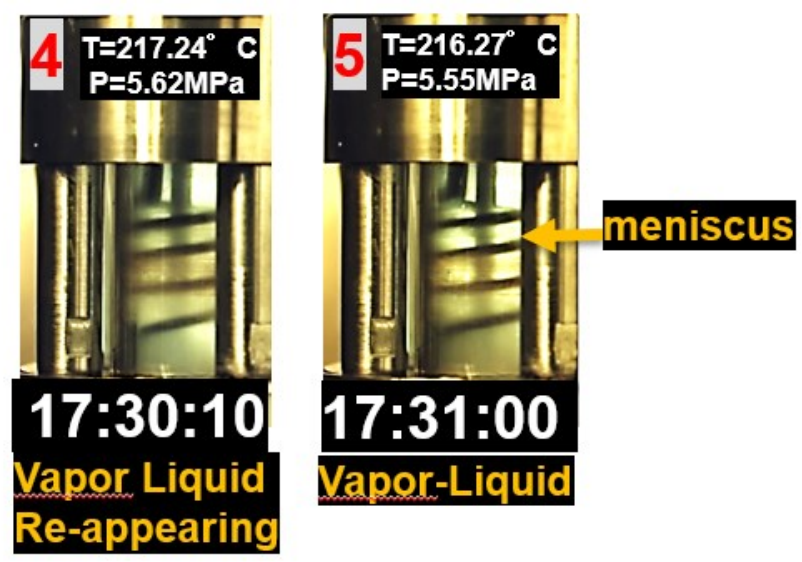

Figure 5. Measurement of the critical point of furan: Photograph numbering with red. 1. Vapor-Liquid Phases, 2. Critical Point and meniscus disappears. System haziness begins to disappear fast 3. Supercritical state, system clear and transparent, 4. Return to Vapor -Liquid - haziness, 5. Vapor and liquid phases. Red box shows location of deposit formed on the sapphire tube inner wall (deposit on all Photographs). 


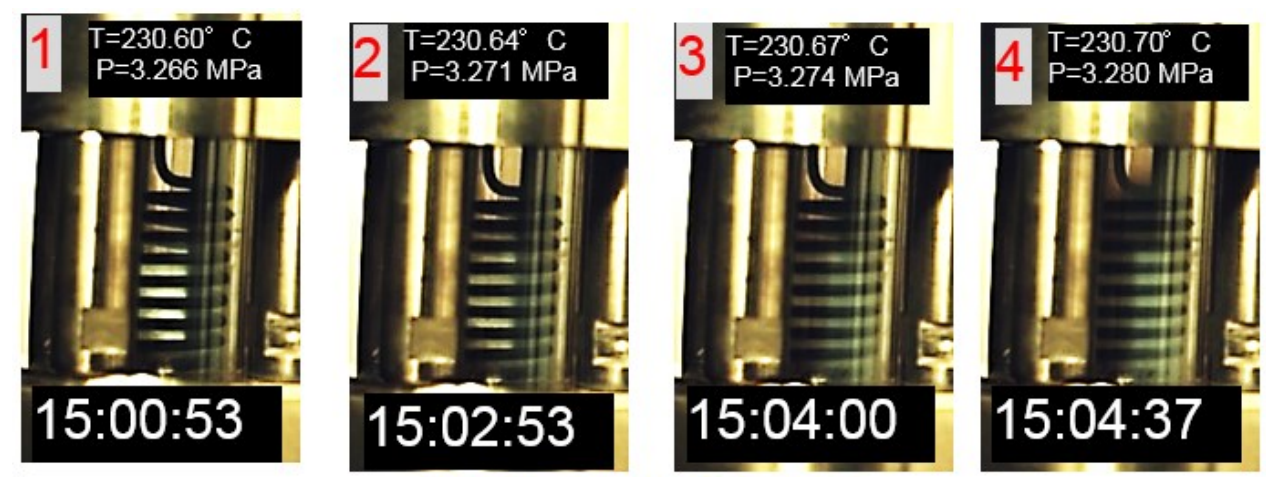

Vapor - Liquid-Behavior

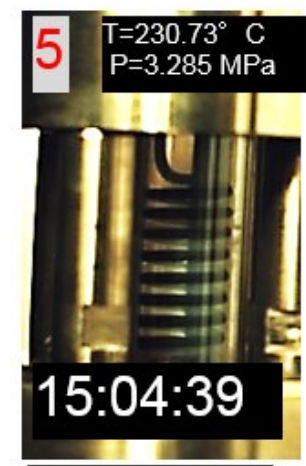

Critical point

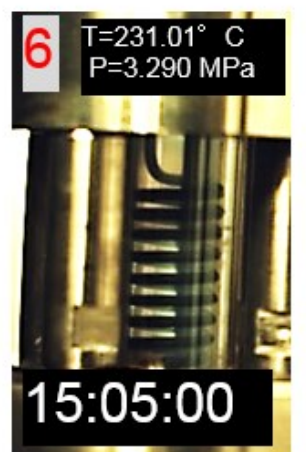

Super Critical

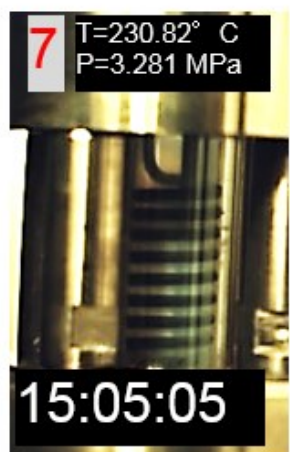

Napor Liquid Re-appearing

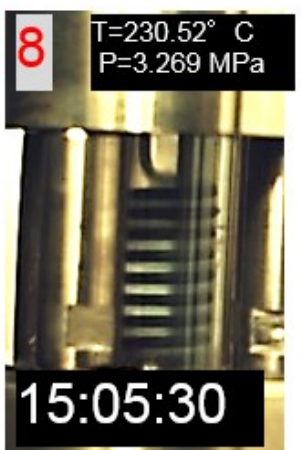

Vapor

Liquid

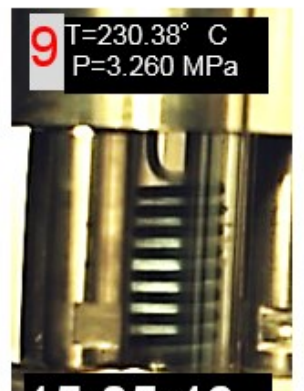

15:05:46

Vapor

Liquid

Figure 6. Measurement of the mixture critical point of $n$-Hexane(1) + Furan, $x(1)=0.878$ : Photograph numbering with red. Photograph numbers from 1 to 4, Vapor-Liquid Phases, 5. Critical Point, haziness disappears rapidly 6. Supercritical state, 7. Return to Vapor -Liquid haziness, 8. Vapor and liquid phases. 9 Vapor-Liquid phases. 


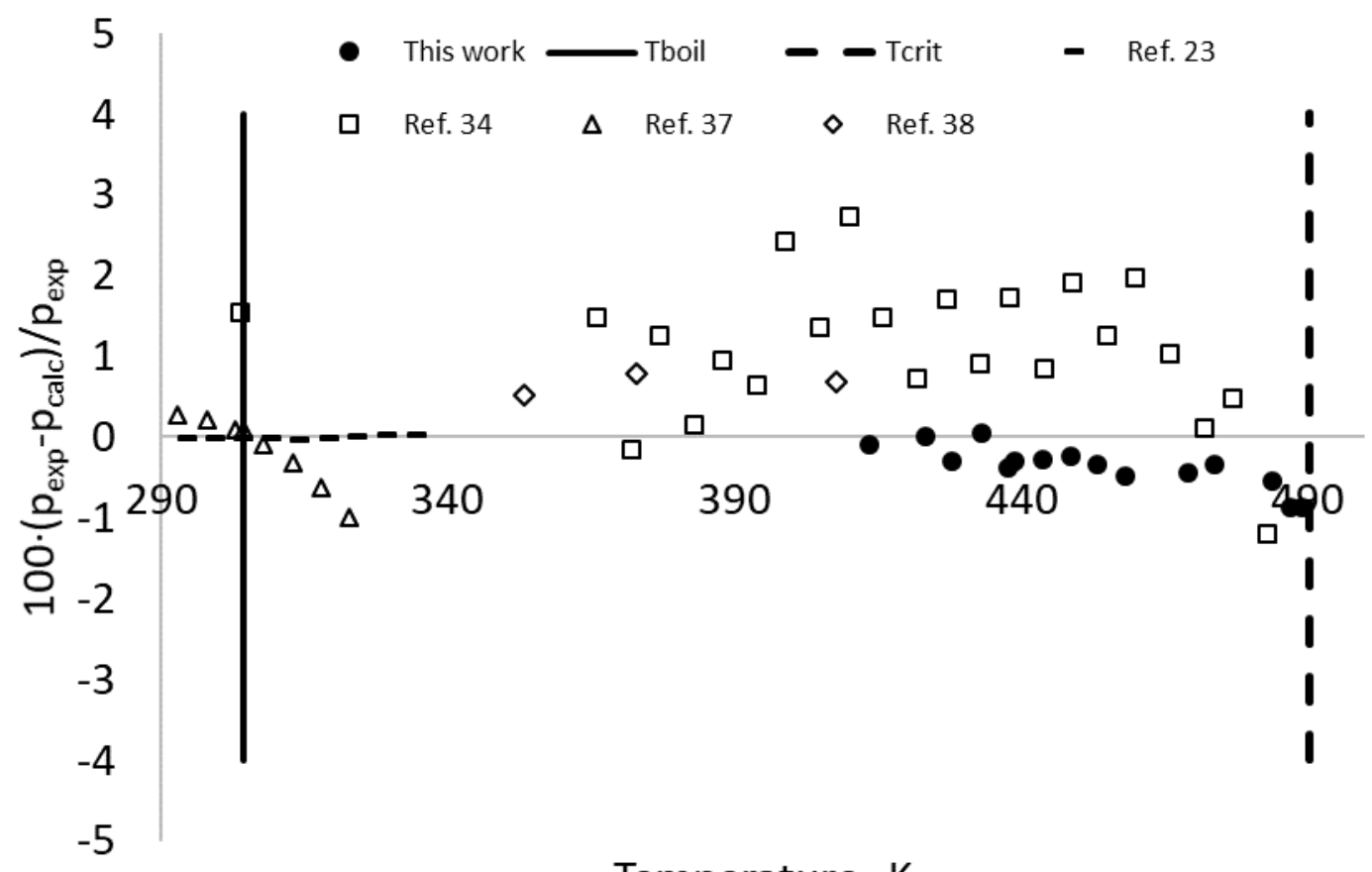

Temperature, $\mathrm{K}$

Figure 7. Vapor pressure deviation plot of Furan. $p_{\text {exp }}$ is experimental pressure, $p_{\text {calc }}$ is the value from the correlation presented in this work. Tboil is the boiling point at 0.101325 $\mathrm{MPa}$; Tcrit is the critical temperature. 


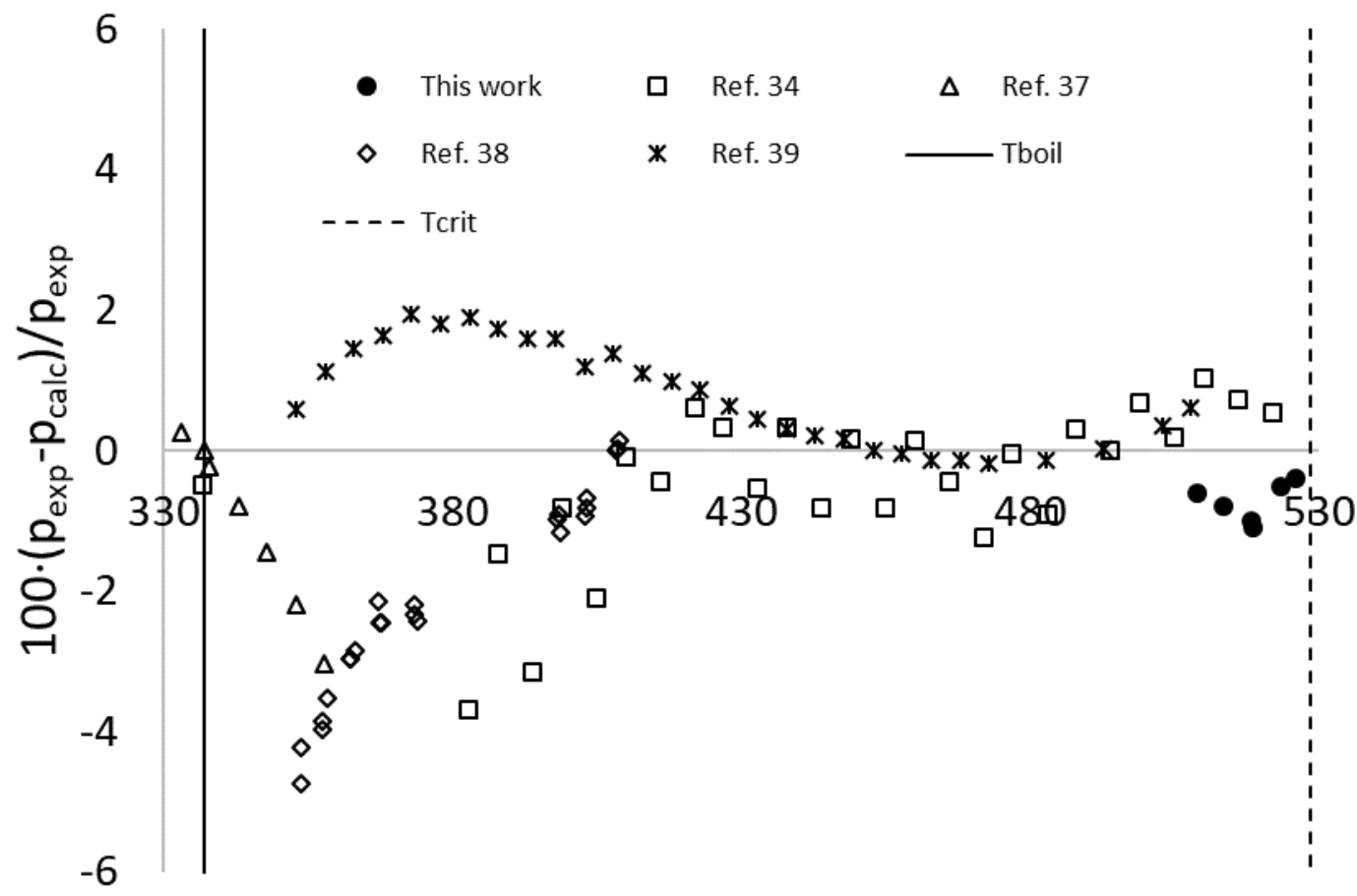

Temperature, $\mathrm{K}$

Figure 8. Vapor pressure deviation plot of 2-Methylfuran. pexp is experimental pressure, $\mathrm{p}_{\text {calc }}$ is the value from the correlation presented in this work, Tboil is the boiling point at $0.101325 \mathrm{MPa}$, Tcrit is the critical temperature. 


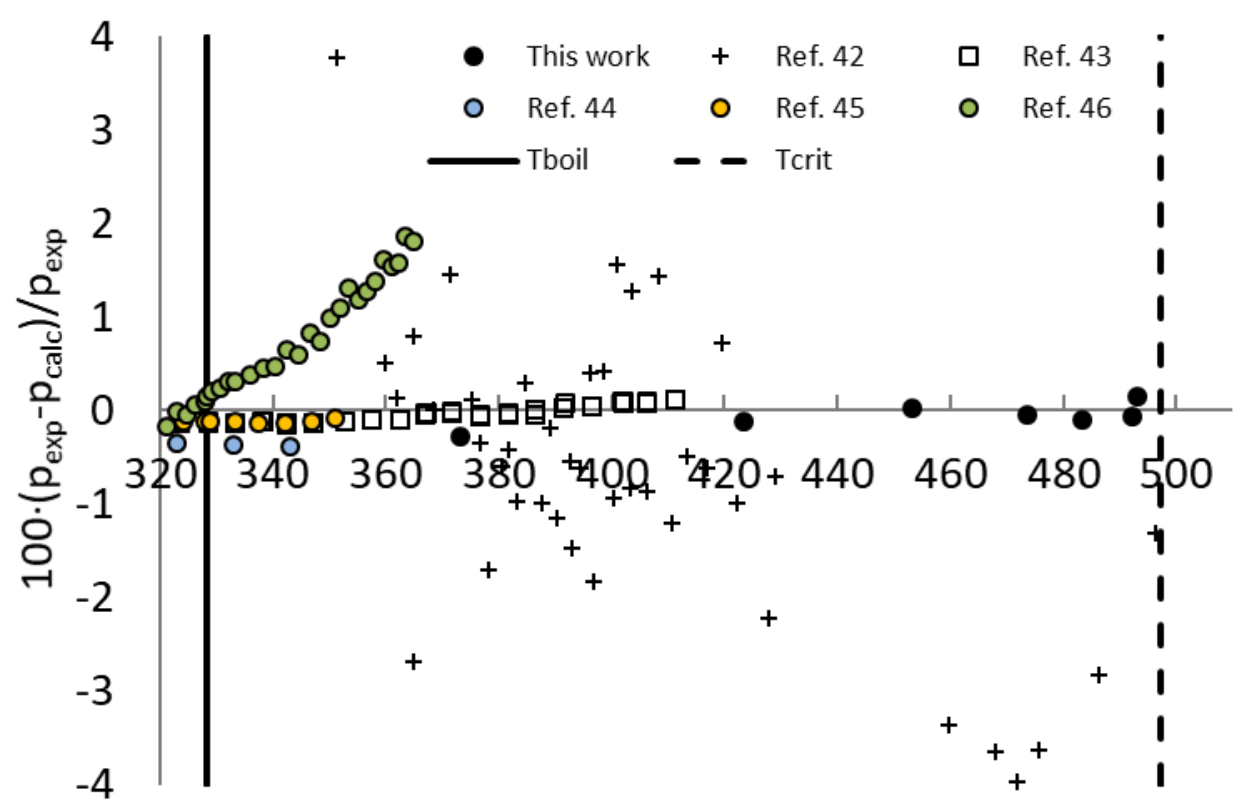

Temperature, $\mathrm{K}$

Figure 9. Vapor pressure deviation plot of 2-methoxy-2-methylpropane. pexp is experimental pressure, $p_{\text {calc }}$ is the value from the correlation presented in this work. Tboil is the boiling point at $0.101325 \mathrm{MPa}$, Tcrit is the critical temperature. 


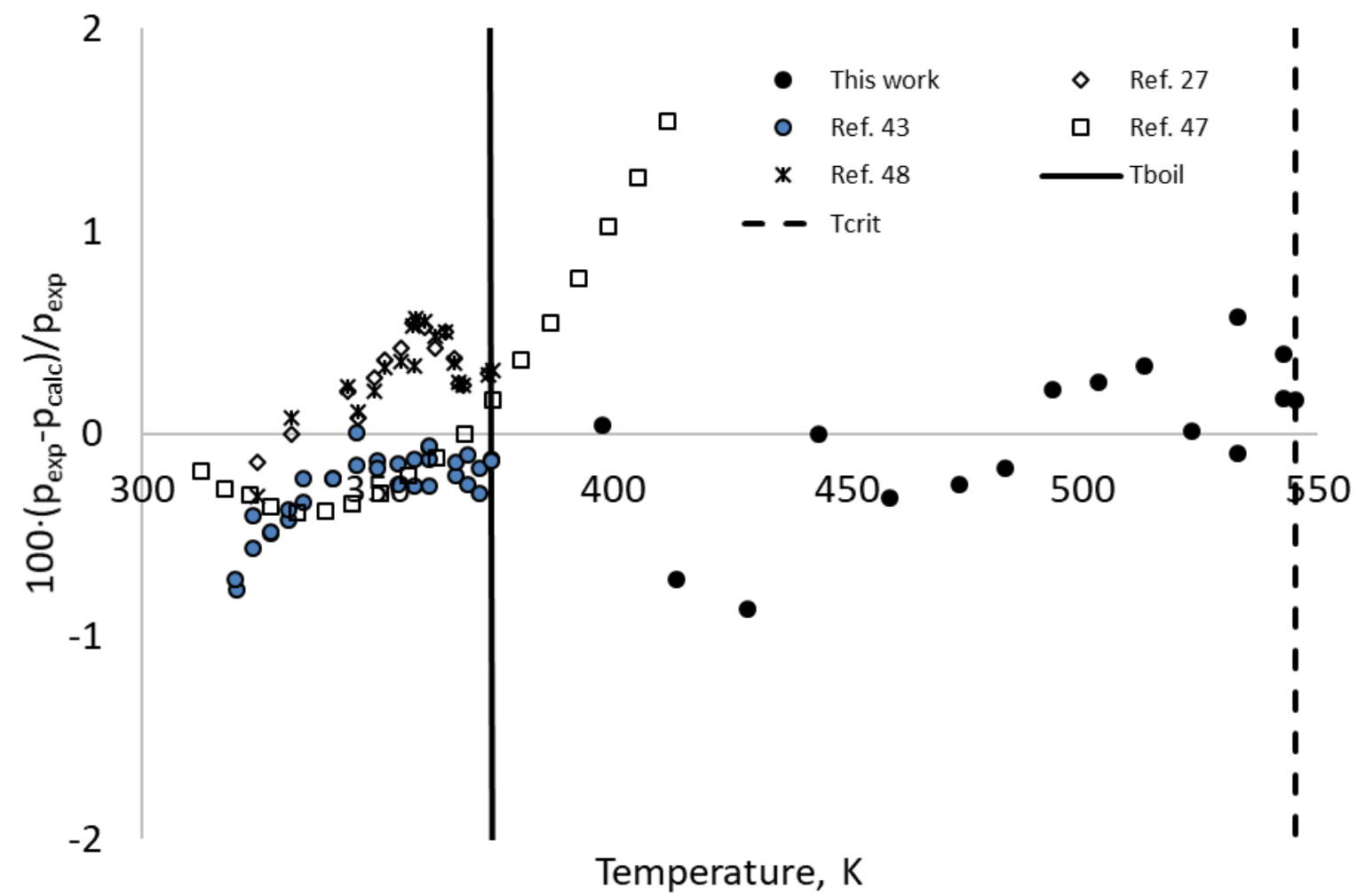

Figure 10. Vapor pressure deviation plot of 2-ethoxy-2-methylbutane. $p_{\text {exp }}$ is experimental pressure, $p_{\text {calc }}$ is the value from the correlation presented in this work. Tboil is the boiling point at $0.101325 \mathrm{MPa}$, Tcrit is the critical temperature. 


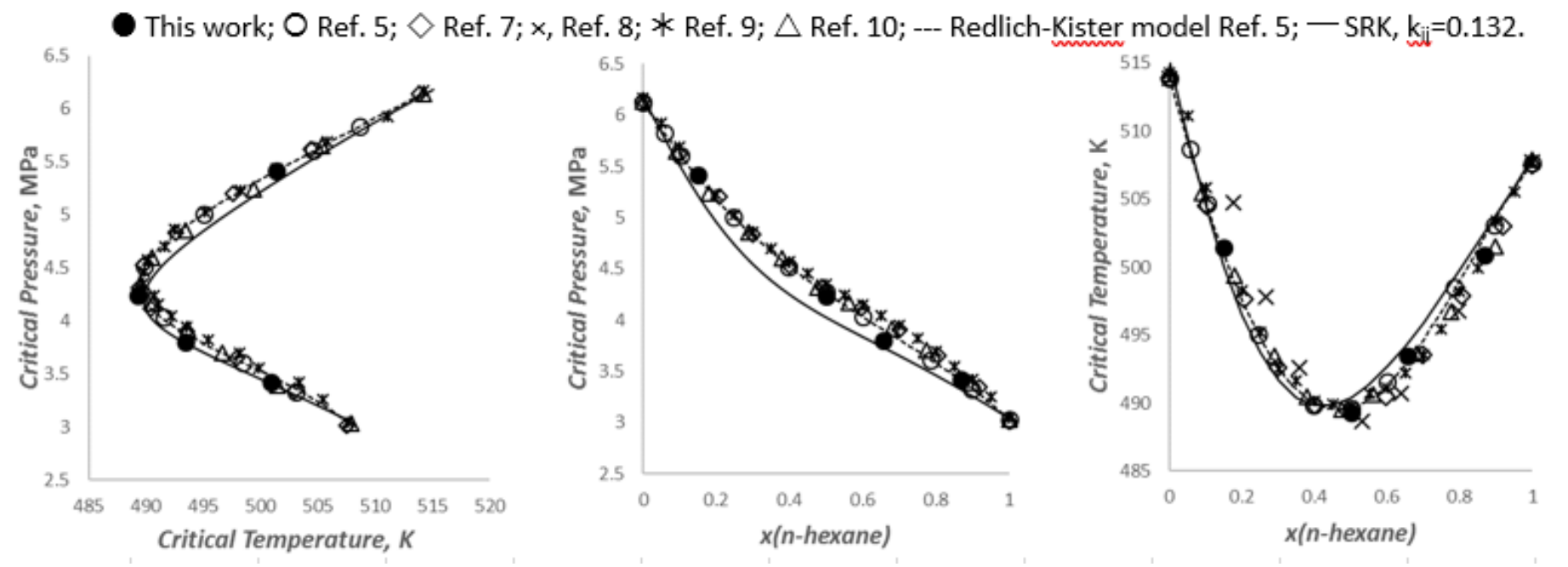

Figure 11. Experimental Critical Temperatures and Pressures of n-hexane + ethanol system. 


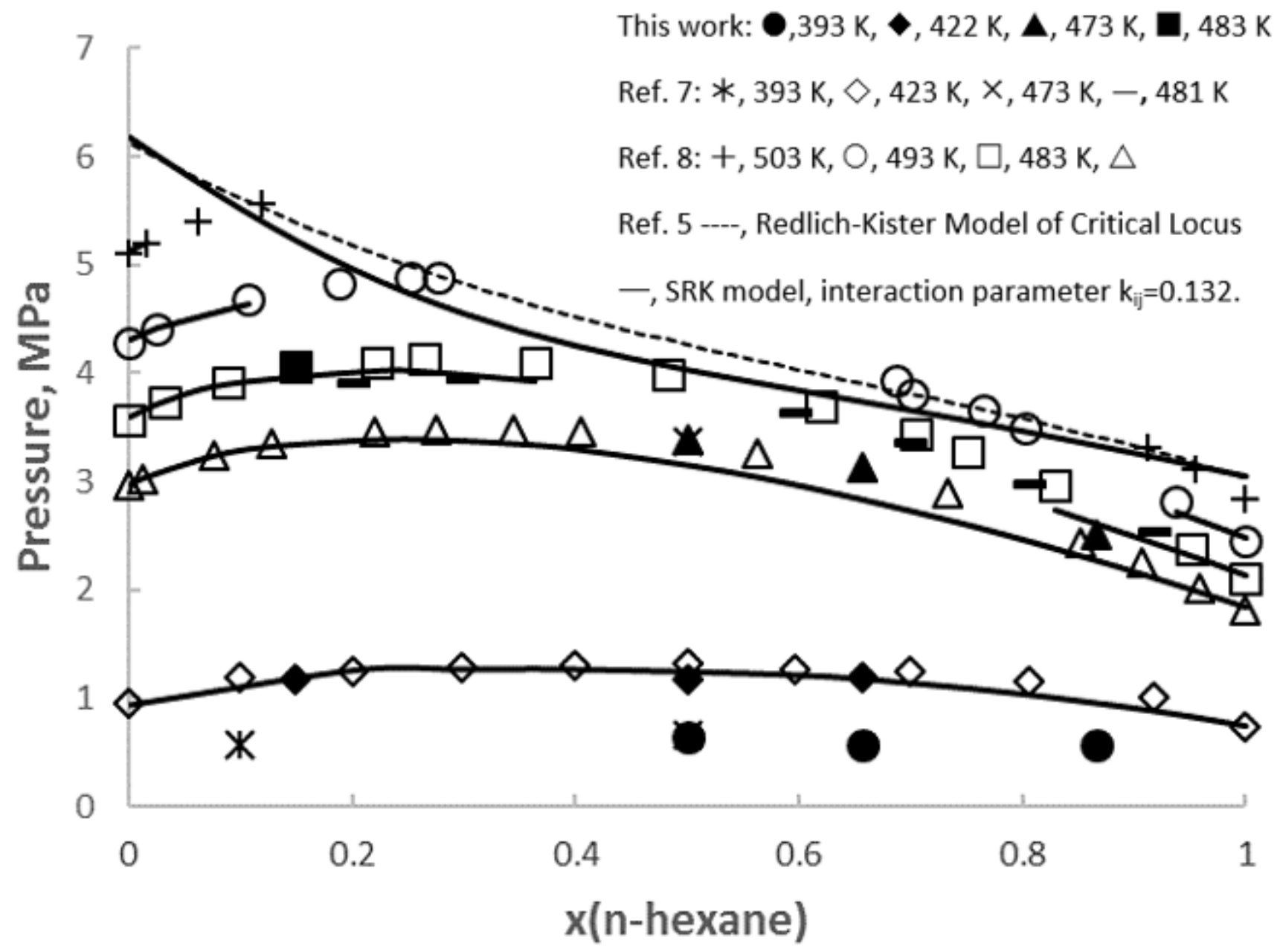

Figure 12. Experimental Bubble Point Pressures of n-hexane + ethanol system. 

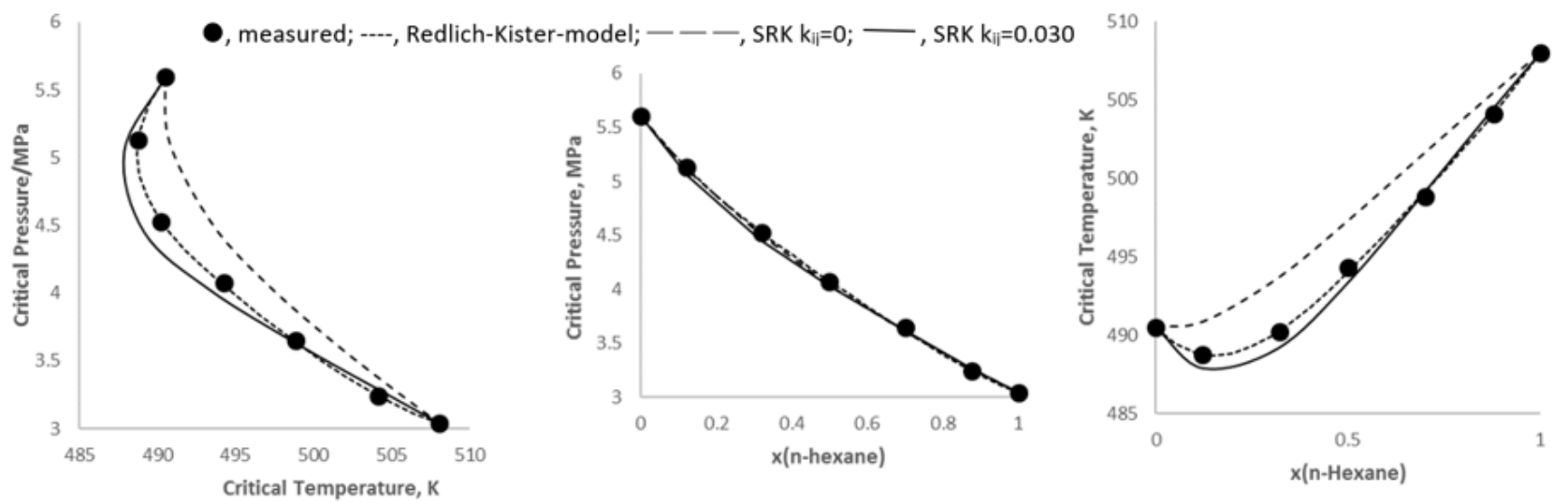

Figure 13: Experimental and modeled Critical Temperatures and Pressures of n-hexane + furan system. 
110th Anniversary: Critical properties and high temperature vapor pressures for furan, 2-methylfuran, 2-methoxy-2-methylpropane, 2ethoxy-2-methylbutane, $n$-hexane and ethanol, and bubble points of mixtures with a new apparatus

Petri Uusi-Kyyny ${ }^{1 *}$, Muhammad Saad Qureshi ${ }^{1}$, Juha-Pekka Pokki ${ }^{1}$, Ville Alopaeus ${ }^{1}$ and Dominique Richon ${ }^{1,2}$

${ }^{1}$ Aalto Univ, School of Chemical Engineering, Department of Department of Chemical and Metallurgical Engineering, FI-00076 Aalto, Finland.

${ }^{2}$ Thermodyn. Res. Unit, School of Chemical Engineering, Howard College Campus, University of KwaZulu-Natal, King George V Avenue, 4041 Durban, South Africa.

*Corresponding author, petri.uusi-kyyny@aalto.fi

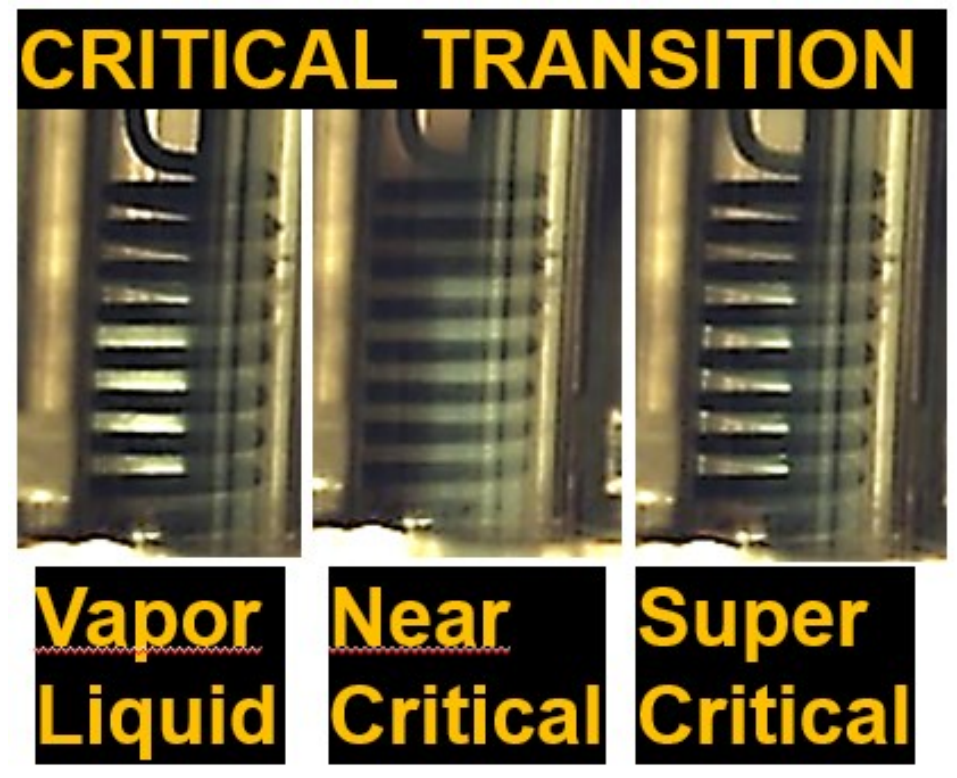

